\title{
Noise as Information for Illiquidity
}

\author{
Grace Xing Hu, Jun Pan, and Jiang Wang*
}

July 1, 2012

\begin{abstract}
We propose a market-wide liquidity measure by exploiting the connection between the amount of arbitrage capital in the market and observed price deviations in U.S. Treasury bonds. During normal times, abundant arbitrage capital smoothes out the Treasury yield curve and keeps the deviations small. During market crises, however, the shortage of arbitrage capital leaves the yields to move more freely relative to the curve, resulting in more "noise" in prices. As such, "noise" in Treasury prices can be informative about the broad market liquidity conditions. Indeed, we find that our "noise" measure captures episodes of liquidity crises of different origins and magnitudes across the financial market, providing information above and beyond existing liquidity proxies. Moreover, using it as a priced risk factor, we show that it helps explain cross-sectional returns on hedge funds and currency carry trades, both known to be sensitive to the general liquidity conditions of the market.
\end{abstract}

${ }^{*} \mathrm{Hu}$ (gracexhu@hku.hk) is from University of Hong Kong, Pan (junpan@mit.edu) and Wang (wangj@mit.edu) are from MIT Sloan School of Management, CAFR, and NBER. We are grateful to Cam Harvey (the editor), the associate editor, two anonymous reviewers, Darrell Duffie, Mark Kritzman, Krishna Ramaswamy, Dimitri Vayanos, Adrien Verdelhan, and Haoxiang Zhu for valuable discussions. We also thank comments from seminar participants at Boston University, Shanghai University of Finance and Economics, University of Maryland, University of Michigan, University of Pennsylvania, University of Western Australia, Capula Investment Management LLC, 2011 NBER Asset Pricing Program Spring Meeting, Moody's 2011 Credit Risk Conference, Morgan Stanley, and Q Group 2012 Spring Conference. 


\section{Introduction}

The level of liquidity in the aggregate financial market is closely connected to the amount of arbitrage capital available. During normal times, institutional investors such as investment banks and hedge funds have abundant capital, which they can deploy to supply liquidity. Consequently, big price deviations from the fundamental values are largely eliminated by arbitrage forces, and assets are traded at prices closer to their fundamental values. During market crises, however, capital becomes scarce and/or willingness to deploy it diminishes. The liquidity in the overall market dries up. The lack of sufficient arbitrage capital limits the force of arbitrage and assets can be traded at prices significantly away from their fundamental values. ${ }^{1}$ Thus, temporary price deviations, or "noise" in prices, being a key symptom of shortage in arbitrage capital, contains important information about the amount of liquidity in the aggregate market. In this paper, we analyze the "noise" in the price of U.S. Treasuries and examine its informativeness as a measure of overall market illiquidity.

Our basic premise is that the abundance of arbitrage capital during normal times helps smooth out the Treasury yield curve and keep the average dispersion low. This is particularly true given the presence of many proprietary trading desks at investment banks and fixedincome hedge funds that are dedicated to relative value trading with the intention to arbitrage across various habitats on the yield curve. ${ }^{2}$ During liquidity crises, however, the lack of arbitrage capital forces the proprietary trading desks and hedge funds to limit or even abandon their relative value trades, leaving the yields to move more freely in their own habitats and resulting in more noise in the yield curve. We therefore argue that these abnormal noises in Treasury prices are a symptom of a market in severe shortage of arbitrage capital. More importantly, to the extent that capital is allocated across markets for major marginal players in the market, this symptom is not only specific to the Treasury market, but also more broadly to the overall financial market.

In addition to its close connection to arbitrage capital, the U.S. Treasury market is ideal for our empirical investigation for several reasons. First, it is a market of central importance and investors of many types come to the Treasury market to trade, not just for investment but also funding needs (Treasuries are probably the most important collateral in short term financing). As such, trading in the Treasury market contains information about liquidity needs for the broader financial market. Second, the fundamental values of Treasury bonds are characterized

\footnotetext{
${ }^{1}$ There is an extensive literature on how the amount of arbitrage capital in a specific market affects the effectiveness of arbitrage forces, or "limits of arbitrage," and possible price deviations. See, for example, Merton (1987), Leland and Rubinstein (1988), Shleifer and Vishny (1997), Gromb and Vayanos (2002), Brunnermeier and Pedersen (2009) and Duffie (2010).

${ }^{2}$ Vayanos and Vila (2009), for example, model the interaction between habitat investors and risk-averse arbitrageurs and its impact on bond yields.
} 
by a small number of interest rate factors, which can be easily captured empirically. This gives us a more reliable benchmark to measure price deviations, and this aspect of the market is important because we would like to keep the information content as "pure" as possible. Other markets such as the corporate bond market, the equity market, or the index options market might also be informative, but their information is "contaminated" by the presence of other risk factors. Third, the U.S. Treasury market is one of the most active and liquid markets, one with the highest credit quality, and is the number one safe haven during crisis. A shortage of liquidity in this market provides a strong signal about liquidity in the overall market.

Using CRSP Daily Treasury database, we construct our noise measure by first backing out, day by day, a smooth zero-coupon yield curve. This yield curve is then used to price all available bonds on that day. Associated with each bond is the deviation of its market yield from the model yield. Aggregating the deviations across all bonds by calculating the root mean squared error, we obtain our noise measure. We call it "noise" only to the extent that in the fixed-income literature, deviations from a given pricing model are often referred to as noise.

Whether this noise measure indeed captures the liquidity condition of the overall market is primarily an empirical matter. If it does, we expect it to exhibit the following properties: First, it should serve as a good indicator during liquidity crises in different parts of the market. Second, it should provide new information about market liquidity beyond various existing liquidity measures. Third and very importantly, given its systematic nature, it should, as an additional risk factor, help us understand returns on assets beyond the Treasury market, especially those which are sensitive to the liquidity condition of the overall market.

Our results show that the noise measure is rather informative about the liquidity condition of the overall market. During normal times, the noise is kept at an average level around 3.61 basis points, which is comparable to the average bid/ask yield spread of 2 basis points. In other words, the arbitrage capital on the yield curve is effective in keeping the deviations within a range that is unattractive given the transaction cost. During crises, however, our noise measure spikes up much more prominently than the bid/ask spread, implying a high degree of misalignment in bond yields that would have been attractive for relative value arbitrage during normal times and are in fact attractive given the contemporaneous transaction cost. These include the 1987 crash, when the noise was over 13 basis points; the aftermath of the LTCM crisis, when the noise peaked at 5.89 basis points; the first trading day after the 9/11 terrorist attack, when the noise was at 12.54; the days following the sale of Bear Stearns to JPMorgan, when the noise peaked at 8.08 basis points; and the aftermath of Lehman default, when the noise was above 15 basis points for a sustained period of time. Given the sample standard deviation of 2.17 basis points for the noise measure, these are large deviations away from the mean. 
To further understand the uniqueness of the information captured by the noise measure, we examine its relation to other known measures of liquidity. One popular measure of liquidity for the Treasury market is the premium enjoyed by on-the-run bonds. Since our noise measure is a daily aggregate of cross-sectional pricing errors, the on-the-run premium is in fact a component of our measure. We find a positive relation between the two, but our noise measure is by far more informative about the overall liquidity condition in the market. In particular, our noise measure spikes up much more prominently than the on-the-run premium during crises. This is because our noise measure collects information over the entire yield curve, while the on-therum premium focuses only on a couple of isolated points on the yield curve. As such, our noise measure is much more sensitive to the commonality of pricing errors across the yield curve. If such commonality heightens during crises, then it will be captured by our noise measure, but not by a measure that focuses only on a couple of isolated points on the yield curve. Indeed, this is how noise becomes information. Our results also show that factors known to be related to systematic liquidity such at the CBOE VIX index and the Baa-Aaa yield spreads have a significant relation with our noise measure. By contrast, term structure variables such as the short- and long-term interest rates and interest-rate volatility do not have strong explanatory power for the time-variation for our noise measure. In other words, the time-variation in our noise measure is not driven by poor yield curve fitting. ${ }^{3}$

It is important to emphasize that our noise measure comes from the U.S. Treasury bond market - the one with the highest credit and liquidity quality and is the number one safe haven during crises, and yet it was able to reflect liquidity crises of varying origins and magnitudes. In this respect, what is captured in our noise measure is not the liquidity concerns specific to the Treasury market. Rather it is a reflection on how different liquidity crises might transmit through financial markets via the movements of arbitrage capital. In other words, rather than being a measure specific only to the Treasury market, our noise measure is a reflection of the overall market condition. ${ }^{4}$ This insight becomes important as we move forward to examine the asset pricing implications of this liquidity risk factor. Asset returns such as equity and bond are within the confined of their own asset classes. While important in explaining the risk factors within their own markets, such standard test portfolios are not good test portfolios for our purpose. What we need are portfolios or trading strategies that transcend the asset class boundaries and are sensitive to liquidity risks or crises across a spectrum of markets. We find hedge fund returns to be ideal for this purpose. They are known to

\footnotetext{
${ }^{3}$ In the appendix, we take up the issue of yield curve fitting more seriously by examining the robustness of our main results using alternative and more flexible curve fitting methods. Our results are robust.

${ }^{4}$ More specifically, our measure is not a reflection of how constrained the market makers in the Treasury market are. In fact, the bid and ask spreads of Treasury bond prices can be a better measure of such "local" liquidity.
} 
be in close association with arbitrage capital, react substantially to market upheavals, and is not localized to just one market.

We use TASS hedge fund data from 1994 through 2011 to obtain hedge fund returns. Using a two-factor model that includes monthly changes in noise as one factor and returns on the stock market portfolio as the other, we find that the liquidity risk is indeed priced by hedge fund returns. The estimated risk premium is statistically significant, and is also economically important. For two hedge funds with the same market beta but differing liquidity beta, one unit difference in liquidity beta generates a difference of $0.69 \%$ per month in returns. This liquidity risk premium explains why some hedge funds can generate superior performance: because of their high exposures to a priced, market-wide liquidity risk factor. Interestingly, such highly exposed hedge funds are also found to have a higher exit rate in 2008 to the graveyard sample. Using other measures of liquidity such as RefCorp yield spread, on-the-run premiums, Pastor-Stambaugh equity market liquidity measure, CBOE VIX, or default spreads to price the same set of hedge fund returns, we find no evidence that any of these liquidity proxies is priced.

We further extend our hedge fund pricing results to explain the performance of currency carry trade - a trading strategy widely known to be linked to arbitrage capital and is sensitive to liquidity conditions in the broad market. A typical currency carry trade is to take long positions on "asset" currencies with high interest rates and fund the trade with "funding" currencies with low interest rates. In our sample, the average return on the "asset" currencies is about 79 basis points a month and is statistically significant. Using our noise measure as a liquidity risk factor, we find that the "asset" currencies have high liquidity exposures, while the "funding" currencies have minimal exposures. Using the liquidity risk premium estimated from hedge fund returns to make risk adjustment, we find that the superior performance of the "asset" currencies is diminished in magnitude and is no longer statistically significant. In other words, high exposure to market-wide liquidity risk is a key driver for currency carry profits.

Our paper contributes to the existing literature in several dimensions. It explores the empirical implications of the theoretical theme on the "limits of arbitrage," which emphasizes the link between shortage of capital, market liquidity and price deviations (see, for example, Merton (1987), Shleifer and Vishny (1997), Kyle and Xiong (2001), and Gromb and Vayanos (2002)). Recent empirical work, such as Coval and Stafford (2007) on equity fire sales by mutual funds and Mitchell, Pedersen, and Pulvino (2007) on convertible bond arbitrage by hedge funds, provides additional empirical evidence on this link. ${ }^{5}$ While these papers focus

\footnotetext{
${ }^{5}$ More recently, Mitchell and Pulvino (2011) provide a detailed and informative account on the financing of hedge funds during the 2008 crisis and its potential implications on asset prices. Nagel (2011) connects the returns of short-term reversal strategies in equity markets with the expected returns from liquidity provision.
} 
mostly on the connection between arbitrage capital and liquidity in specific markets, our paper considers the liquidity in the overall market. In particular, our liquidity measure is able to capture episodes of liquidity crises of varying origins and is not limited to one specific market. As such, the fluctuation of arbitrage capital captured by our noise measure is not confined to market makers of certain markets, or hedge funds of certain styles.

A growing body of work explores asset pricing implications of liquidity and liquidity risk. This includes, for example, Pastor and Stambaugh (2003) and Acharya and Pedersen (2005) on equities, Bao, Pan, and Wang (2011) on corporate bonds and Mancini, Ranaldo, and Wrampelmeyer (2012) on foreign currencies. ${ }^{6}$ These studies follow a common approach, which is to focus on a specific market to both construct and test the liquidity risk measure. We instead focus on the liquidity risk of the overall market by extracting our liquidity measure from the U.S. Treasury market, one of the most liquid markets in the world. We then use test portfolios from other markets, namely hedge fund and currency carry trade strategies, to confirm the importance of this aggregate liquidity risk factor in asset pricing.

Our results also complement studies on hedge fund and carry trade returns. ${ }^{7}$ For example, Sadka (2010) extracts a liquidity risk factor from the equity market and finds it to be important in explaining hedge fund returns. His measure of liquidity risk, similar to that of Pastor and Stambaugh (2003), is based on price impact in the equity market, thus is equity specific, while ours is more market-wide. Moreover, we do not find a significant risk premium for the PastorStambaugh equity liquidity risk factor using hedge fund returns as test portfolios. Since Fama (1984), the source of currency carry trade returns has been an object of investigation by many studies. $^{8}$ Brunnermeier, Nagel, and Pedersen (2008) focus on interaction of crash risks of currencies and funding conditions of currency speculators. Using CBOE VIX and LIBOR

Fleckenstein, Longstaff, and Lustig (2010) find that the prices of nominal Treasury bonds and TIPS appear to be inconsistent with inflation swaps and document a large increase of this mis-pricing during the 2008 crisis. Lou, Yan, and Zhang (2012) find that anticipated and repeated Treasury auctions can generate temporary price deviations in the secondary market.

${ }^{6}$ Jankowitsch, Nashikkar, and Subrahmanyam (2011) also propose a dispersion-based liquidity measure for corporate bonds. For each bond, they calculate root mean squared difference between the TRACE prices and the respective Markit quotation and find it to be informative about the bond's liquidity. Although similar in name, it is important to point out that their dispersion comes from the intraday price movements (one bond at a time) and has a very different economic meaning from the noise measure proposed in this paper.

${ }^{7}$ There is a growing literature in hedge fund studies that connects hedge fund activities to market liquidity and market crises such as Cao, Chen, Liang, and Lo (2010) and Billio, Getmansky, and Pelizzon (2010).

${ }^{8}$ It ranges from using consumption-based asset pricing models (e.g., Backus, Gregory, and Telmer (1993) and Verdelhan (2010)), reduced-form term structure models (e.g., Backus, Foresi, and Telmer (2001)), to, more recently, combining carry trade returns with currency options to incorporate tail risks (e.g., Jurek (2009) and Burnside, Eichenbaum, Kleshchelski, and Rebelo (2010)). 
spreads as proxies for funding liquidity, they find that the carry trade tends to incur losses during weeks in which illiquidity increases. Our result is consistent with this observation, but more importantly, we are able to formally test the pricing implication. In particular, our result explicitly links the superior performance of "asset" currencies to their high exposures to the noise measure.

Finally, given the existing literature, we discuss the extent to which our noise measure may be driven by the liquidity demand (instead of liquidity supply) in the Treasury market. In order to address this issue, we first note that the price noise of a particular security arises from the imbalance of the demand and supply of liquidity in this security. The demand for liquidity comes from the transitory buying or selling pressures of this security, while the supply of liquidity comes from market makers/arbitragers who accommodate these pressures. Hence, a spike in the price noise of a particular security (or a subset) can come from an increase in liquidity demand, a decrease in liquidity supply, or both. In this respect, it is only when the liquidity demand of a particular security stays relatively stable, can we attribute an increase in noise of this particular security to a decrease in liquidity supply. But one unique feature of our noise measure is that it is averaged across a broad set of Treasury securities. As a result, shocks to the liquidity demand of individual Treasuries are mostly averaged away and do not yield to a spike in the noise measure. ${ }^{9}$ By contrast, the situation for liquidity supply is different because arbitrage capital does not localize itself to one security. In particular, when arbitrage capital is abundant, liquidity shocks to individual Treasuries are averaged away as capital moves fluidly across the yield curve. But when there is an overall shortage of arbitrage capital, liquidity supply becomes limited across the board, and our noise measure is uniquely designed to capture this effect. ${ }^{10}$ Consequently, we expect the noise measure to be more reflective of the overall liquidity supply in the Treasury market but less so of liquidity demand.

The paper proceeds as follows. Section 2 describes the construction of our noise measure from Treasury prices. In Section 3, we report the time series properties of the noise measure, focusing in particular on its variation through various crises and its connection with other measures of market liquidity. In Section 4, we provide the cross-sectional tests on our noise measure as a liquidity risk factor using returns on hedge funds and use the pricing results to explain currency carry profits. Section 5 concludes. In the appendix, we investigate the robustness of our main results with respect to curve-fitting methods.

\footnotetext{
${ }^{9} \mathrm{~A}$ common shift in the buying or selling of Treasury securities will cause a shift in the yield curve rather than average noise.

${ }^{10}$ This unique feature of our noise measure also sets itself apart from measures such as on-the-run premiums, which focus only on a few isolated points on the yield curve. Not surprisingly, we find that our noise measure is much more informative about the overall liquidity condition in the market.
} 


\section{Constructing the Noise Measure}

\subsection{Treasury Data}

We use the CRSP Daily Treasury database to construct our noise measure. The main variable we use from the dataset is the daily cross-sections of end-of-day bond prices from 1987 through 2011. The dataset itself starts from January 1962, but we choose to start the sample from 1987 due to considerations over both data quality and the sample period of interest. In particular, we will test our noise measure using hedge fund data, which is available only from 1990. Our sample consists of Treasury bills, notes and bonds that are noncallable, non-flower and with no special tax treatment. Observations with obvious pricing errors such as negative prices, negative yields, or negative bid/ask spreads are deleted from the sample. We dropped Treasury securities with remaining maturities less than 1 month because of the potential liquidity problems. We also drop bonds with maturity longer than 10 years to base our noise measure on notes and bonds with maturity between 1 and 10 years. For bonds with maturity long than 10 years, we have fewer observations and the fitted yield curve becomes less reliable.

Table 1 provides the details of our bond sample. On average, we have 163 bonds (including notes) and bills every day to fit the yield curve and 109 bonds with maturity between 1 and 10 years to construct the noise measure. The cross-section varies over time, with a noticeable dip around late 1990s and early 2000s. This coincided with record surpluses of US government and the reduction of gross issuance of Treasury notes and bonds, which fell by 54 percent from 1996 to 2000. Also reported are the key characteristics of the bonds used in constructing the noise measure. For example, the average maturity of the bonds is 3.85 years and the average age of the bonds is 3.96 years. Over time, both variables remain stable, alleviating the concern that the time-series variations in bond characteristics such as maturity and age might cause the time-series variation in our noise measure. Also reported in Table 1 is the average spread between bid and ask yields of the bonds used in our noise construction. The average bid/ask spread is 2.11 basis points, with a decreasing time trend that is caused by both improved liquidity in the market and improved data quality. In particular, after October 16, 1996, the source for price quotations of the CRSP Treasury database changed to GovPX, which receives its data from 5 inter-dealer bond brokers, who broker transactions among 37 primary dealers. For most of the bond characteristics reported in Table 1, the cross-sectional mean and median are close, indicating that the cross-section of bonds is unlikely to be dominated by a few bonds with extremely different characteristics. 


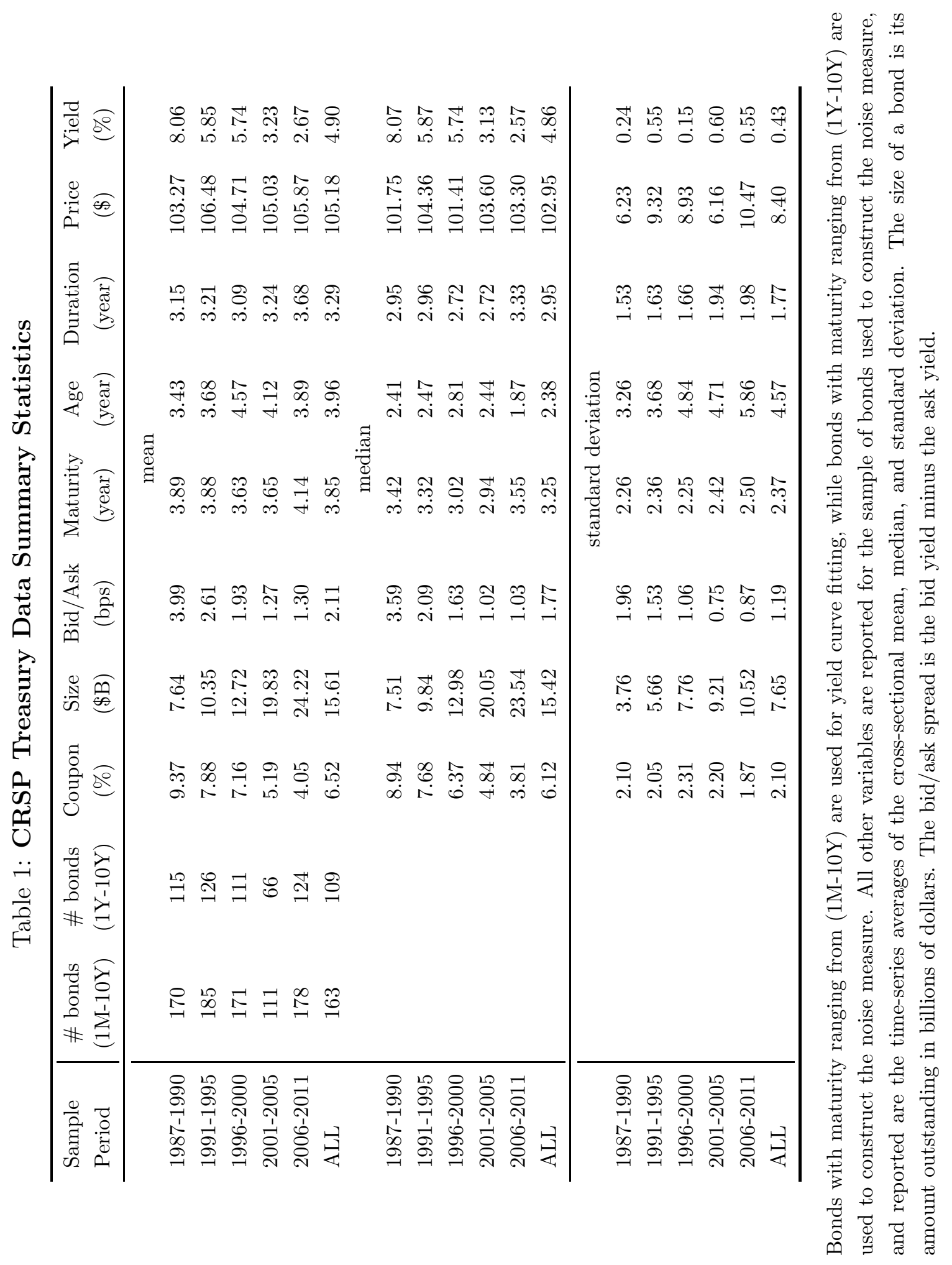




\subsection{Curve Fitting}

Various estimation methods can be employed to back out zero-coupon yield curves from coupon-bearing Treasury securities. These approaches can be broadly classified into splinebased and function-based models. Spline-based methods rely on piecewise polynomial functions that are smoothly joined at selected knots to approximate the yield curve. Functionbased models, on the other hand, use a single parsimonious parametric function to describe the entire yield curve. In this section, we will employ a function-based model, and later in the appendix, we will revisit the issue of curve fitting. We will employ a variety of spline-based methods to reconstruct our noise measure and check the robustness of our main results. We will show that our main results are not specific to the particular curve-fitting method employed here. Instead, they are quite robust to various curve-fitting methods and the main insight of our paper is quite general.

Popular models in the class of function-based models include Nelson and Siegel (1987) and Svensson (1994). We choose the Svensson model because of its improved flexibility over the Nelson-Siegel model. The Svensson model assumes the following functional form for the instantaneous forward rate $f$ :

$$
f(m, b)=\beta_{0}+\beta_{1} \exp \left(-\frac{m}{\tau_{1}}\right)+\beta_{2} \frac{m}{\tau_{1}} \exp \left(-\frac{m}{\tau_{1}}\right)+\beta_{3} \frac{m}{\tau_{2}} \exp \left(-\frac{m}{\tau_{2}}\right),
$$

where $m$ denotes the time to maturity and $b=\left(\beta_{0} \beta_{1} \beta_{2} \beta_{3} \tau_{1} \tau_{2}\right)$ are model parameters to be estimated. Given that $f \rightarrow \beta_{0}$ as $m \rightarrow \infty$ and $f \rightarrow \beta_{0}+\beta_{1}$ as $m \rightarrow 0$, it follows that $\beta_{0}$ represents the forward rate at infinitely long horizon, and $\beta_{0}+\beta_{1}$ represents the forward rate at maturity zero. In addition, $\left(\beta_{2}, \tau_{1}\right)$ and $\left(\beta_{3}, \tau_{2}\right)$ control the "humps" of the forward rate curve, while $\beta_{2}$ and $\beta_{3}$ determine the magnitude and direction of the humps, and $\tau_{1}$ and $\tau_{2}$ affect the position of the humps. Finally, in order to model nominal interest rates, a proper set of parameters must satisfy the conditions that $\beta_{0}>0, \beta_{0}+\beta_{1}>0, \tau_{1}>0$ and $\tau_{2}>0$.

Using the parameterized forward curve, we can derive the corresponding zero-coupon yield curve, which can then be used to price any coupon-bearing bonds. Conversely, we can use market prices of such bonds to back out the model parameters $b$. Specifically, on each day $t$, the inputs of our curve fitting are the market closing prices (mid bid/ask quotes) of all Treasury bills and bonds in our sample with maturity between one month and ten years. The output of the curve fitting on that day is the vector of model parameters $b_{t}$, and the details of curve fitting are as follows.

Let $N_{t}$ be the number of bonds and bills available on day $t$ for curving fitting and let $P_{t}^{i}, i=1, \ldots, N_{t}$, be their respective market observed prices. We choose the model parameters $b_{t}$ by minimizing the weighted sum of the squared deviations between the actual and the 
model-implied prices:

$$
b_{t}=\underset{b}{\operatorname{argmin}} \sum_{i=1}^{N_{t}}\left[\left(P^{i}(b)-P_{t}^{i}\right) \times \frac{1}{D_{i}}\right]^{2},
$$

where $P^{i}(b)$ is the model-implied price for bond $i$ given model parameters $b$ and $D_{i}$ is the MaCaulay's duration for bond $i{ }^{11}$ Following the standard practice in the yield curve fitting literature, we weight the price deviations by the inverse of bond duration. Effectively, we are minimizing pricing errors in the yield space. ${ }^{12}$

\subsection{Noise Measure}

We construct our noise measure using the zero-coupon curve backed out from the daily crosssection of bonds and bills. For each date $t$, let $b_{t}$ be the vector of model parameters backed out from the data. Suppose that, on date $t$, there are $N_{t}$ Treasury bonds with maturity between 1 and 10 years. For each of these $N_{t}$ bonds, let $y_{t}^{i}$ denote its market observed yield, and let $y^{i}\left(b_{t}\right)$ denote its model-implied yield. As a measure of dispersions in yields around the fitted yield curve, we construct our noise measure by calculating the root mean squared distance between the market yields and the model-implied yields: ${ }^{13}$

$$
\text { Noise }_{t}=\sqrt{\frac{1}{N_{t}} \sum_{i=1}^{N_{t}}\left[y_{t}^{i}-y^{i}\left(b_{t}\right)\right]^{2}} .
$$

Unlike in curving fitting, where qualified bonds and bills with maturity between 1 month and 10 years are used, we use only bonds with maturity between one and ten years in constructing the noise measure. While short-maturity bonds and bills are needed for fitting the short end of the yield curve, we feel that their information content is limited with respect to the availability of arbitrage capital in the overall market. This is because the short end of the yield curve is known to be noisier than other parts of the yield curve, primarily due to temporary demand/supply fluctuations in that segment of of the market. Moreover, the short end is unlikely to be the object of arbitrage capital, which is the main motivation of our noise measure. While the longer maturity bonds might be useful to further capture the effect

\footnotetext{
${ }^{11}$ We use the daily MaCaulay's duration reported by CRSP.

${ }^{12}$ Unlike minimizing directly in the yield space, this approach has the advantage of avoiding large computing costs required by numerically converting prices into yields. In an earlier version of our paper, we also performed curve fitting by minimizing pricing errors without duration weights. Our main results are robust with respect to both curve fitting approaches.

${ }^{13}$ In addition to measuring noise in the yield space, we also experimented with using squared pricing errors scaled by duration, as in equation (2). Our main results are robust to both approaches of noise measures.
} 
of fixed-income relative value trades, the supply of these bonds is not as stable and might introduce unnecessary time-series noise to our measure. ${ }^{14}$ For this reason, we exclude bonds with maturity longer than 10 years in constructing the noise measure.

To avoid having the pricing errors of one or two bonds driving the noise measure, we also put in place a filter. Specifically, given the daily cross-section of bonds and their pricing errors, we calculate the cross-sectional dispersion in pricing error in the yield space. Any bond with yield to maturity 4 standard deviations away from the model yield is excluded from the construction of the noise measure. In practice, this is a rather mild filter and affects only one or two bonds when triggered. More specifically, from 1987 through 2011, this filter was triggered on $24.4 \%$ of the days to remove one bond each day, on $8.0 \%$ of the days to remove two bonds each day, on $2.7 \%$ of the days to remove three bonds each day, and on $0.67 \%$ of the days to remove four bonds each day. There was no incident when this filter removed more than four bonds. As reported in Table 1, there are on average 105 bonds contributing to the daily noise measure. Consequently, the noise measure is a collective measure of the entire yield curve and should not be driven by only one or two bonds. This additional filter allows us to take out the few outliers that were missed in our initial sample cleaning process. Indeed, as the data quality improves over time, this filter was triggered even less frequently. For example, from 1994 through 2011, the sample period during which we will later perform our pricing tests using hedge-fund returns, this filter was triggered only on $20.34 \%$ of the days to remove one bond, $1.80 \%$ of the days to remove two bonds, and only once to remove three bonds. There was no incident when this filter removed more than three bonds over this sample period. ${ }^{15}$

To further illustrate the construction of our noise measure and the information content it is supposed to capture, we plot in Figure 1 several examples of par-coupon yield curves and the market-observed bond yields. The top left panel in Figure 1 plots three random days in 1994, which represent normal days in terms of curve fitting. As can be seen, our curve fitting method does a reasonable job. The other panels in Figure 1 focus on the days surrounding five events including the 1987 stock market crash, the 1998 LTCM crisis, the September 11, 2001 terrorist attack, the 2005 GM/Ford downgrade, and the Lehman default in September 2008. For all of these events, we see significant increases in our noise measure. More importantly, as shown in the cross-sectional plots, the sudden increases were not the result of poor curve

\footnotetext{
${ }^{14}$ For example, issuance of the 30-year Treasury bonds was suspended for a four and a half year period starting October 31, 2001 and concluding February 2006.

${ }^{15}$ To understand the robustness of our hedge-fund pricing results, we also experimented with cutoffs of other magnitudes. For example, our hedge fund results still hold with a threshold of 6 standard deviations, when the winsorizing removes, at a monthly frequency, only one bond (out of the cross-section of over 100 bonds) 5 times (out of the full sample of 216 months).
} 

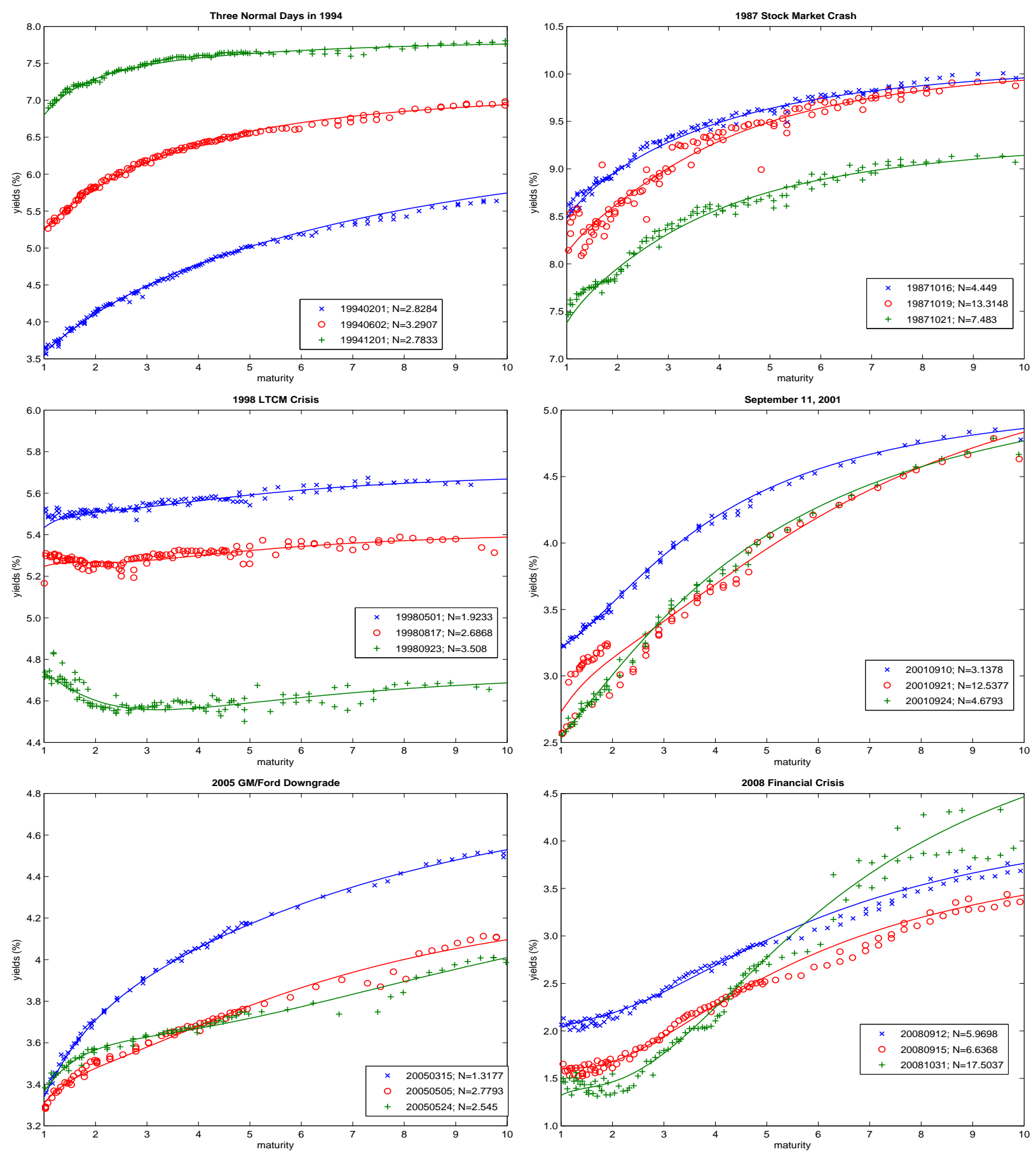

Figure 1: Examples of par-coupon yield curves and the market-observed bond yields, marked by "x", "o", or "+". The top left panel plots three random days in 1994, and the other five panels focus on the days surrounding five events: the 1987 stock market crash, the 1998 LTCM crisis, the September 11, 2001 terrorist attack, the 2005 GE/Ford downgrade, and the Lehman default in September 2008. Marked in the legends are the date of observation and the level of the noise measure for that day. 
fitting on these event days. Instead, they were caused by high levels of dispersion in bond yields across the entire yield curve. In fact, a closer examination of this dispersion seems to indicate comovement in dispersion within various bond habitats.

\section{Time-Series Properties}

\subsection{Noise as Information for Liquidity Crises}

The daily time-series variation of our noise measure is plotted in Figure 2. The most interesting aspect of this plot is the rich information content embedded in a variable that has been traditionally treated as just noise or pricing errors. During normal times, the noise measure fluctuates around its time-series average of 3.61 basis points with a standard deviation of 2.17 basis points, and it is highly persistent, with a daily autocorrelation of $98.11 \%$ and a monthly autocorrelation of $90.75 \%$. This level of noise and its fluctuation is in fact comparable to the average spread between bid and ask yields of 2.11 basis points for the same sample of bonds. In other words, the arbitrage capital on the yield curve is effective in keeping the deviations within a range that is unattractive given the transaction cost.

During crises, however, our noise measure spikes up much more prominently than the bid/ask spread, implying a high degree of mis-alignment in the yield curve that would have been attractive for relative value trading during normal times and are in fact attractive given the contemporaneous transaction cost. This includes the 1987 crash, when the noise was over 13 basis points; the aftermath of the LTCM crisis, when the noise peaked at 5.89 basis points; the first trading day after 9/11 terrorist attack, when the noise was at 12.54; the days following the sale of Bear Stearns to JPMorgan, when the noise was peaked at 8.08 basis points; and the aftermath of Lehman default, when the noise was above 15 basis points for a sustained period of time. Given its sample standard deviation of 2.17 basis points, these are large deviations away from the mean.

Another interesting aspect captured by our noise measure is that while some liquidity events, such as the 1987 crash or the 9/11 terrorist attack, are short lived, others take much longer to play out. The Savings \& Loan crisis in the late 80's and early 90's is one such example, and the aftermath of the Lehman default on September 15, 2008 is another example. Figure 3 provides a closer examination of our noise measure during the period after Lehman default. It shows that when Lehman defaulted on Monday, September 15, 2008, the noise measure was at 6.64, which was about one standard deviation above the historical mean. Compared with the Friday before when the noise measure stood at 5.97, it was only a mild increase, especially give the severity of the event. ${ }^{16}$ But as shown in Figure 3, the Lehman event was the beginning of

\footnotetext{
${ }^{16}$ From 1987 to 2011, the sample standard deviation of daily changes in noise measure is 0.42 basis points.
} 


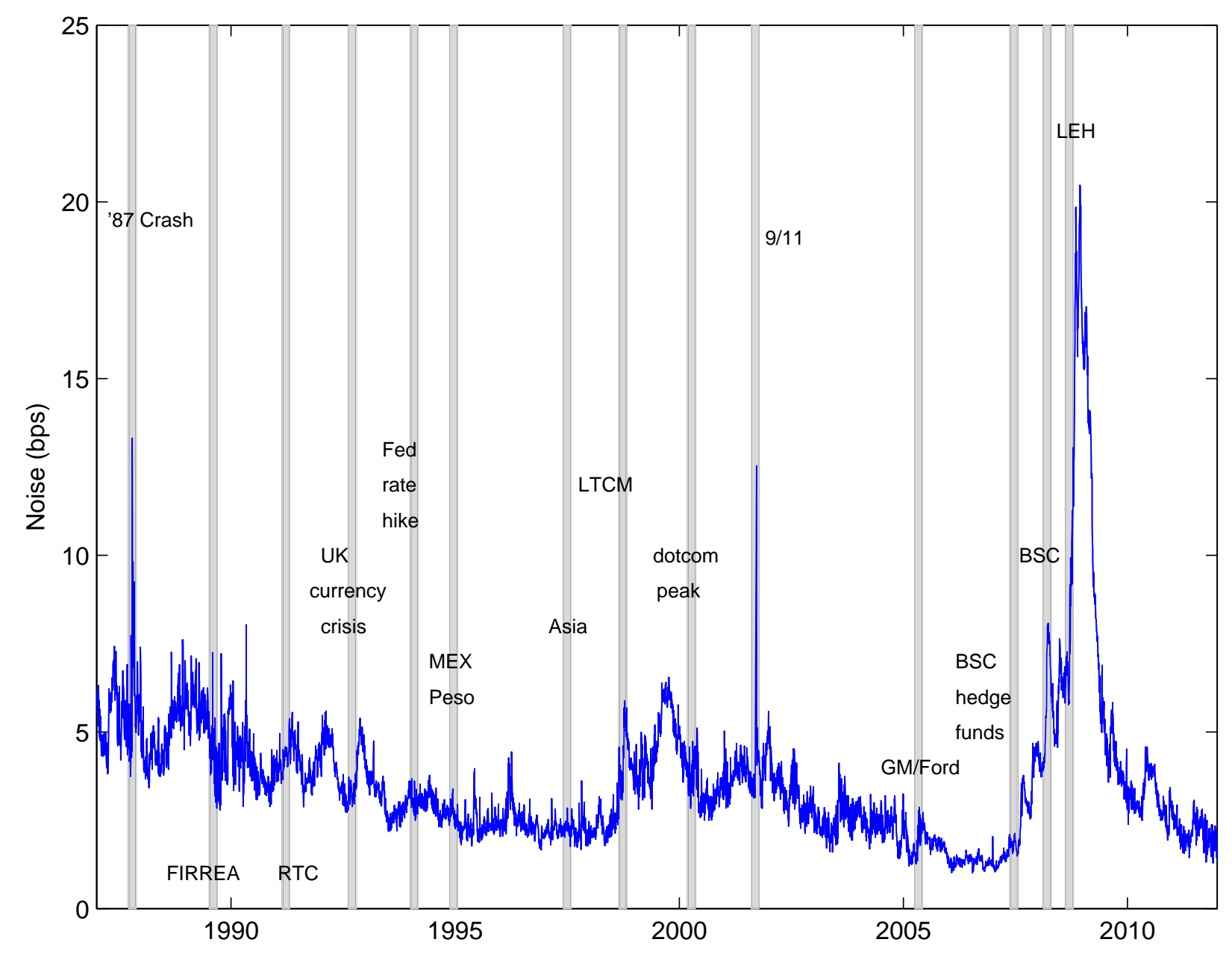

Figure 2: Daily time-series of the noise measure (in basis points).

a cycle of worsening liquidity that lasted until late April and early May of 2009, when Federal Reserve announced and implemented stress tests for large U.S. banks. During this period of liquidity crisis, the noise measure had two noticeable peaks whose magnitudes dwarfed any of the previous crises. The first one was in early November when it peaked at 19.85 on November 6 , days after Treasury and Fed injected $\$ 125$ billion of capital into 9 large US Banks via the Capital Purchase Program (CPP), and the creation of the Commercial Paper Funding Facility $(\mathrm{CPFF})$. The second one was at the middle of December when the noise measure peaked at 20.47 on December 10 as concerns over the financial crisis deepened. Overall, this period was when the crisis was at its worst and this fact was captured by our noise measure.

It is worth emphasizing that our noise measure comes from the U.S. Treasury bond market - the one with the highest credit and liquidity quality and is the number one safe haven during crises, and yet it was able to reflect liquidity crises of varying origins and magnitudes. In this 


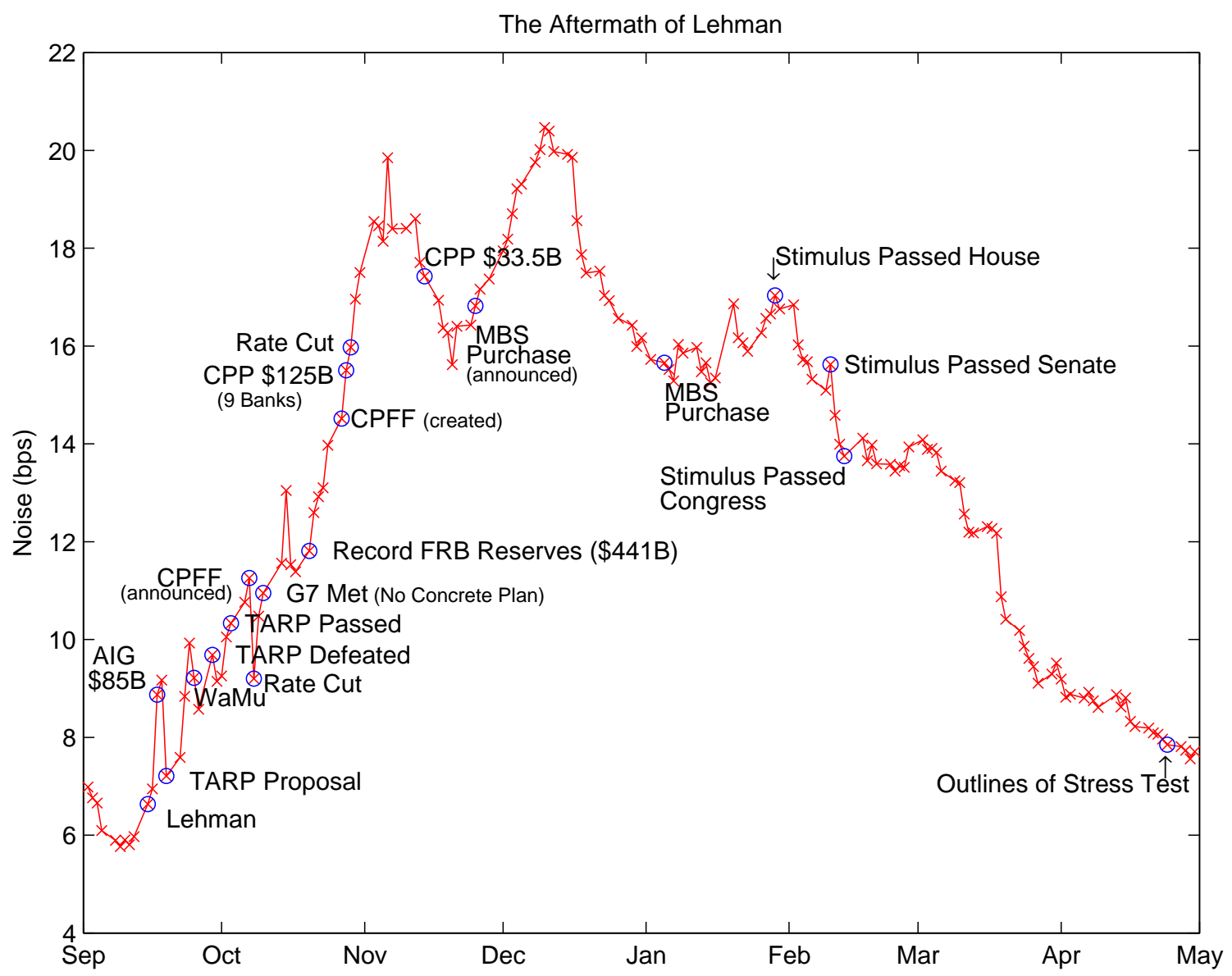

Figure 3: Daily time-series of the noise measure in late 2008 and early 2009. TARP: Troubled Asset Relief Program; CPP: Capital Purchase Program; CPFF: Commercial Paper Funding Facility; and the MBS Program is Fed's $\$ 1.25$ trillion program to purchase agency mortgagebacked securities.

respect, what is captured in our noise measure is not the liquidity concerns specific to the Treasury market, but liquidity conditions across the overall financial market.

\subsection{Noise and the On-the-Run Premium}

One popular measure of liquidity with respect to the Treasury market is the on-the-run and off-the-run premium: the just issued (on-the-run) Treasury bond enjoys a price premium, therefore lower yield, compared to old bonds with similar maturities. Since our noise measure is a daily aggregate of cross-sectional pricing errors, the on-the-run premium is in fact a component of our measure. Calculating the correlation between daily changes of our noise measure and daily changes of the on-the-run premium, we find that the correlation is $5.7 \%$ 
and $9.3 \%$, respectively, for the five- and ten-year on-the-run premiums. Repeating the same calculation at a month frequency, the correlation increases to $33.4 \%$ and $42.8 \%$, respectively. Overall, we see a positive relationship between our noise measure and the on-the-run premium, which is relatively small at the daily frequency but grows larger at the monthly frequency.

Moreover, while the noise measure is on average smaller than the on-the-run premium, it tends to spike up much more significantly during crises. For example, on October 19, 1987, the noise measure was 4.47 standard deviations above its sample average, while the five-year on-the-run premium was 0.51 standard deviations above from its sample average and the ten-year on-the-run premium was 0.04 standard deviation below its sample average. On September 21, 2001, the first bond trading day after the terrorist attack, our noise measure was 4.11 standard deviations above while the five- and ten-year on-the-run premiums were 0.58 and 1.58 standard deviations above, respectively. On October 15, 2008, when the crisis after Lehman's default deepened, our noise measure was 4.34 standard deviations above while the ten-year premium was 4.63 standard deviations above and the five-year premium was 0.64 standard deviation below its sample average.

This comparison between our noise measure and the on-the-run premium is instructive as it accentuates the important fact that the information captured by our noise measure is a collective information over the entire yield curve. ${ }^{17}$ The fact that our noise measure spikes up during liquidity crises much more prominently than the on-the-run premiums implies that there is commonality in the pricing errors across the entire yield curve. And the heightened commonality during crises is reflected in noisy and mis-aligned yield curves, which are captured by our noise measure. This is how noise could become informative. By contrast, a couple of isolated points on the yield curve as captured by the on-the-run premiums will not be as informative.

\subsection{Noise and Other Measures of Liquidity}

To further investigate the connection between our noise measure and other measures of market liquidity, we report in Table 2 results of OLS regression of monthly changes in our noise measure on several important market variables. The regressions are done first univariately, and then in multivariate form in the last column to compare their relative contribution. The pairwise correlations of monthly changes of these variables are reported in Table 3.

\footnotetext{
${ }^{17}$ This observation sets our paper apart from the recent work by Musto, Nini, and Schwarz (2011) and Lamoureux and Theocharides (2012), who focus on the relative pricing in the market for 10-year Treasury notes. Consistent with our finding, both paper find substantial pricing deviations in the 10-year region during the recent financial crisis. Over the entire sample, however, the information content of our measure differs from theirs exactly because our measure is a collective information over the entire yield curve.
} 


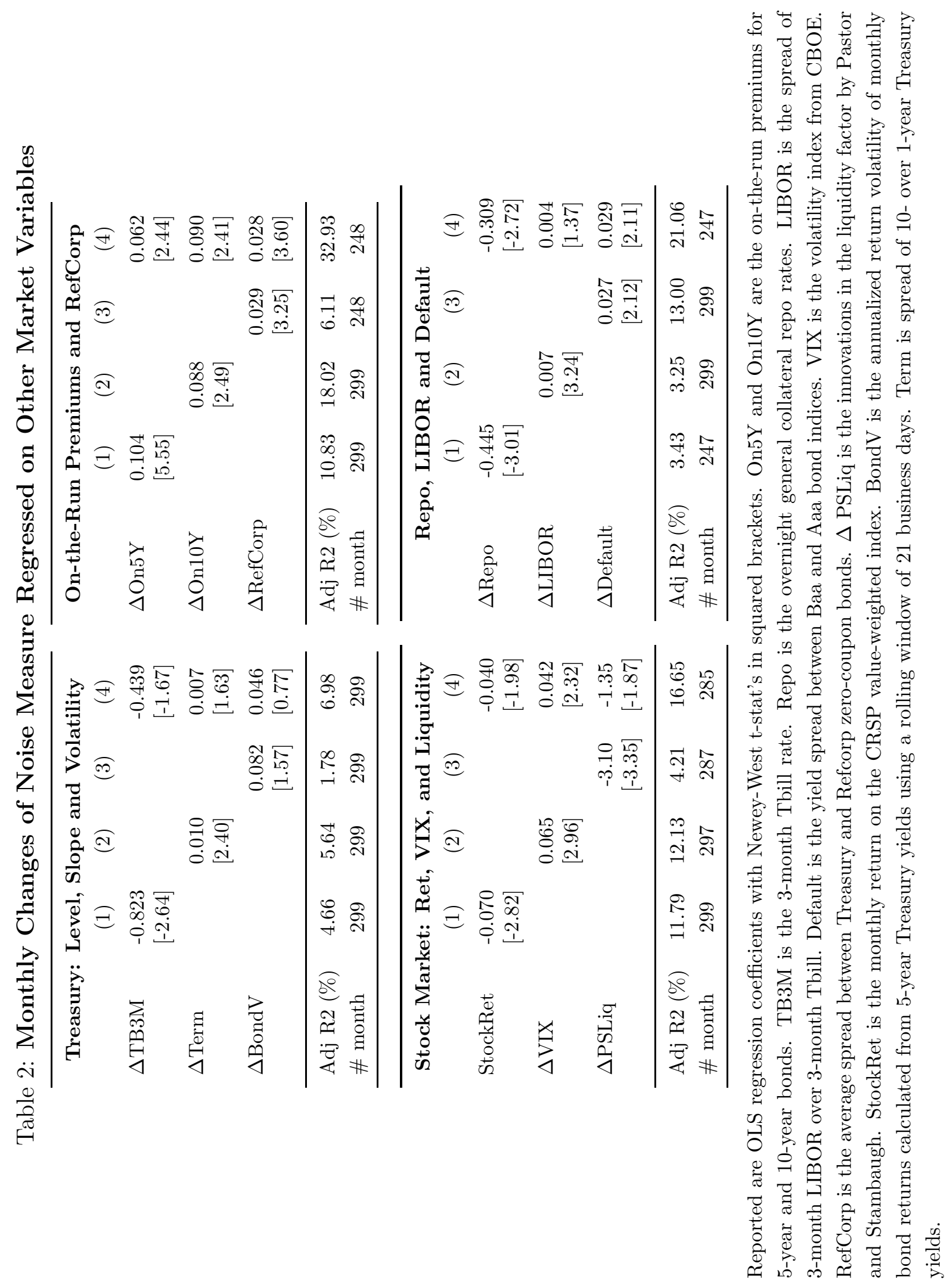


Table 3: Pairwise Correlations (in \%)

\begin{tabular}{|c|c|c|c|c|c|c|c|c|c|c|c|c|c|}
\hline & & 2 & 3 & 4 & 5 & 6 & 7 & 8 & 9 & 10 & 11 & 12 & 13 \\
\hline 1 & $\Delta$ Noise & -22 & 33 & 43 & 15 & 24 & -20 & 25 & 19 & 36 & 35 & -21 & -35 \\
\hline 2 & $\Delta \mathrm{TB} 3 \mathrm{M}$ & & -18 & -14 & -25 & -50 & 39 & -12 & -38 & -14 & -25 & 27 & 17 \\
\hline 3 & $\Delta \mathrm{On} 5 \mathrm{Y}$ & & & 13 & 30 & 17 & -15 & 5 & 14 & -7 & 29 & -23 & -25 \\
\hline 4 & $\Delta \mathrm{On} 10 \mathrm{Y}$ & & & & -6 & 14 & 0 & 1 & 6 & 24 & 20 & -11 & -14 \\
\hline 5 & $\Delta$ BondV & & & & & 21 & -24 & 21 & 24 & -5 & 29 & -30 & -12 \\
\hline 6 & $\Delta$ Term & & & & & & -32 & 6 & 12 & -6 & 4 & -15 & -4 \\
\hline 7 & $\Delta$ Repo & & & & & & & -19 & -19 & -9 & -2 & 11 & -0 \\
\hline 8 & $\Delta$ RefCorp & & & & & & & & 17 & 21 & 5 & -23 & -7 \\
\hline 9 & $\Delta \mathrm{LIBOR}$ & & & & & & & & & 8 & 25 & -17 & -22 \\
\hline 10 & $\Delta$ Default & & & & & & & & & & 23 & -2 & -31 \\
\hline 11 & $\Delta \mathrm{VIX}$ & & & & & & & & & & & -29 & -69 \\
\hline 12 & $\Delta$ PSLiq & & & & & & & & & & & & 31 \\
\hline 13 & StockRet & & & & & & & & & & & & \\
\hline
\end{tabular}

Pairwise correlations are computed using monthly changes from 1987 through 2011 and reported in percentage. See Table 2 for definitions of variables.

\section{Treasury Market: Level, Slope and Volatility}

First, we examine the connection between our noise measure and the Treasury market variables including the level, slope, and volatility of interest rates. Since our noise measure is computed as pricing errors in yields, it is important to make sure that the time-variation in the noise measure is not caused by time-variations in interest rates. Results are summarized in the top left panel of Table 2. Regressing monthly changes of our noise measure on monthly changes in three-month TBill rates, we find a negative and statistically significant relation. This implies increasing illiquidity during decreasing short rates, which is consistent with the fact that liquidity in the overall market typically worsens during episodes of flight to quality and decreasing interest rates. The explanatory power of the short rate for our noise measure, however, is rather limited. As shown in Table 2, the R-squared of the regression is only $4.66 \%$. Another important factor in the Treasury market is the slope of the term structure, which is labeled as Term in Table 2. We find a positive relation between our noise measure and the term spread, which is consistent with the observation that the slope of the term structure steepens in the depth of economic recessions. This connection, however, is not very strong and the R-squared of the regression is only $5.64 \%$.

Overall, although our noise measure is constructed using pricing data in the Treasury market, its connection to the time-variation in bond yields is not very strong. In fact, this is a good indication for the "purity" of our noise measure. Otherwise, high correlations with such 
term-structure pricing variables might be an indication that our curve fitting is not flexible enough to capture the shapes of the term structure.

Similarly, given that our noise measure captures the cross-sectional dispersion in Treasury bonds, it is natural to ask whether or not it is purely driven by the volatility of this market. To check this, we regress monthly changes of our noise measure on monthly changes in bond volatility, which is calculated as the annualized bond return volatility using a rolling window of 21 business days. We find that a positive relation between our noise measure and bond volatility, but it is not statistically significant. In particular, bond volatility can only explain $1.46 \%$ of the monthly variation in our noise measure. In other words, the information contained in our noise measure is not driven just by the volatility in the Treasury bond market. In fact, a large component of our noise measure is unrelated to the volatility of the Treasury market. ${ }^{18}$

\section{Treasury Market: Liquidity and Flight-to-Quality Premiums}

One important measure of liquidity premium for the Treasury market is proposed by Longstaff (2004), who compares Treasury bonds with bonds issued by RefCorp, a US government agency guaranteed by the Treasury. He finds a large liquidity premium in Treasury bonds, and documents the presence of a flight-to-liquidity premium in Treasury bonds. This measure examines the symptom of illiquidity from a perspective that is very different from ours, but is indeed very much related. It is therefore interesting to see how this measure connects with ours. For this, we construct RefCorp spread by calculating the average spread between RefCorp and Treasury zero-coupon bonds with maturities ranging from 3 months to 30 years. As shown in the top right panel of Table 2, regressing monthly changes of our noise measure on monthly changes in RefCorp spread, we find a positive and statistically significant connection. In other words, when the flight-to-liquidity premium in the Treasury market increases, the illiquidity of the overall market as captured by our noise measure also increases. But this positive relation is not very strong given that RefCorp spread can explain only $6.11 \%$ of the monthly changes in our noise measure. In other words, while it is possible that the flight-toliquidity premium in the Treasury market contributes to our noise measure, it is only a small fraction of the information captured by the noise measure.

The variable with a relatively high explanatory power for our noise measure is the 10year on-the-run premium, which can explain $18.02 \%$ of the monthly variation in our noise

\footnotetext{
${ }^{18}$ Acknowledging the fact that the bond volatility is a monthly estimate, we also average our noise measure over each month and regress the monthly changes of this averaged noise measure on bond volatility. Again, the coefficient is positive but insignificant and the R-squared is only $1.58 \%$. We also used swaption implied volatility instead of the historical bond return volatility. Regressing monthly changes in noise measure on monthly changes in in-3month-for-5year swaption implied volatility, we find the slope coefficient to be positive with a t-stat of 1.90 and the R-squared of this regression is $4.38 \%$.
} 
measure. The 5-year on-the-run premium is also positively related to our noise measure and can explain $10.83 \%$ of its monthly variation. This not surprising since the on-the-run premium is a component of our noise measure. In fact, the significance of this result is that a large component of our noise measure is not captured by the on-the-run premium and this uncaptured component has more information content for liquidity conditions of the broad market (see Section 3.2 for a more extensive discussion). Adding on-the-run premiums together with RefCorp spread in a multivariate regression, we see that together, they explain changes in the noise measure with an adjusted R-squared of $32.93 \%$.

\section{Stock Market: Returns, VIX, and Liquidity}

One liquidity factor shown to be important in the US equity market is the one constructed by Pastor and Stambaugh (2003). This liquidity measure is an aggregate of individual-stock liquidity measures proposed by Campbell, Grossman, and Wang (1993), using the idea that order flow induces greater return reversals when liquidity is lower. Given the systematic nature of this liquidity measure and given the importance of the US equity market, it is worth examining how this measure relates to our noise measure, which is designed to capture to overall market liquidity condition including the stock market. As shown in the bottom left panel of Table 2, this measure of liquidity has a statistically significant relation with our noise measure. The coefficient is negative, implying that a negative shock to the systematic liquidity factor in the equity market is likely to be accompanied by an increase in our noise measure and worsening liquidity of the overall market. The R-squared of the regression is $5.67 \%$, implying that the liquidity effect captured by the noise measure cannot be explained by the liquidity of the equity market only. Nevertheless, given that these two measures are constructed using data from two distinctively different markets, this level of comovement indicates the presence and the importance of a systematic liquidity factor.

The CBOE VIX index, constructed from S\&P 500 index options, is often referred to as the "fear gauge." 19 We find a positive and statistically significant relation between the VIX index and our noise measure. The R-squared of this regression is $12.13 \%$. In other words, an increase in the "fear gauge" is likely to be accompanied by an increase in our noise measure. Given its significant relation with our noise measure, it is important for us to distinguish the relative contribution between the two. We will visit this issue in Section 4, using hedge fund returns as testing portfolios to evaluate their relative importance.

We also find a negative and significant relation between the US stock market returns and our noise measure. In other words, our noise measure spikes up during worsening stock

\footnotetext{
${ }^{19}$ We used the old VIX index (VXO) since the new VIX is only recently introduced and the sample extends back only to 1990, while the old VIX has been around longer and sample extends back to 1986 .
} 
market conditions. The R-squared of this regression is 11.79\%, Adding the Pastor-Stambaugh stock market liquidity measure together with the VIX index and stock market returns in a multivariate regression, we find that they can explain the changes in the noise measure with an adjusted R-squared of $16.65 \%$.

\section{Credit Market: Default and LIBOR Spreads}

The bottom right panel of Table 2 examines the connection between our noise measure and default spreads, measured as the difference in yield between Baa and Aaa rated bonds. We find a positive and significant relation, and the R-squared of the regression is $13 \%$. This result is consistent with the possibility that liquidity risk is an important component of the observed default spreads. We perform a bi-variate OLS regression by including both the default spreads and the VIX index - two variables with high explanatory power for our noise measure and are often used as proxies for liquidity. We find the slope coefficients for both variables to be positive and statistically significant, and the adjusted R-squared is $20.21 \%$. In other words, these popular proxies of liquidity are both related to our noise measure, but can explain only a very limited amount of the time variation of our noise measure. ${ }^{20}$

Table 2 also reports the connection with overnight general collateral Repo rates and LIBOR spreads. Overall, the results are in the expected direction. For example, our noise measure increases with increasing LIBOR spreads, while our noise measure is negatively related with the repo rates. Including the Repo rates, LIBOR spreads, and default spreads in a multivariate regression, we find that the repo rates and default spreads remain significant and the adjusted R-squared of the regression is $21.06 \%$.

\section{All Together}

Finally, when the 5-year and 10-year on-the-run premiums, the RefCorp spread, the VIX index, stock market returns, the Pastor-Stambaugh liquidity factor, and default spreads are put together in one regression, they can collectively explain $43.7 \%$ of the monthly variation of our noise measure. In other words, over $50 \%$ of the uncertainty in our noise measure is left unexplained. Our results in the next section will show that it is this unexplained component that is important in explaining cross-sectional hedge fund returns.

\footnotetext{
${ }^{20}$ Indeed, as will be shown later in Section 4, our noise measure has important pricing implications and commands a significant risk premium. Moreover, this result remains robust using a component of our noise measure that is orthogonal to VIX and default spreads. By contrast, we do not find strong pricing implications for VIX or default spreads.
} 


\section{Cross-Sectional Pricing Tests}

Our noise measure is designed to capture the lack of liquidity in the overall market. The empirical evidences provided so far indicate that this noise measure indeed does a good job in capturing the aggregate liquidity risk. Given the systematic nature of this risk, we now investigate its asset-pricing implications, particularly its impact on asset returns. In order to better identify this impact, we need to consider returns that are potentially sensitive to the market-wide liquidity shocks. For this purpose, we employ two sets of returns for our tests. The first set consists of returns on hedge funds, whose trading activities cover a broad spectrum of asset classes and whose capital adequacy is a good representation of the amount of arbitrage capital available in the market. The second set of returns are those from currency carry trades, which are also known to be connected with the overall arbitrage capital in the market.

\subsection{Hedge Fund Returns as Test Portfolios}

\section{Hedge Fund Data}

We obtain hedge fund returns, assets under management (AUM), and other fund characteristics from the Lipper TASS database. The TASS database divides funds into two categories: "Live" and "Graveyard" funds. The "Live" hedge funds are active ones as of the latest update of the TASS database, in our case February 2012. Hedge funds are listed as "Graveyard" funds when they stop reporting information to the database. Fund managers may decide not to reporting their performance for a number of different reasons such as liquidation, merger or closed to new investment. Although TASS has been collecting data since late 1970s, the Graveyard database was created much later in 1994. We thus choose our sample period from 1994 through 2011 to mitigate the impact of survivorship bias.

We only include funds that report returns net of various fees in US dollars on a monthly basis, which covers a majority of the funds in TASS. We also require that each fund has at least $\$ 10$ million assets under management, and at least 24 months of return history during our sample period. This ensures that we have a sample of hedge funds of reasonable size and each fund has a long enough time-series for meaningful regression results. ${ }^{21}$ The details of our hedge fund sample are summarized in Table 4.

\footnotetext{
${ }^{21}$ As mentioned in Cao, Chen, Liang, and Lo (2010), smaller funds with AUM less than $\$ 10$ million are of less concern from an institutional investor's perspective, and they have less impact on the market as well. But we do experiment with different size criteria such as $\$ 5$ million, $\$ 50$ million, and $\$ 100$ million. Our main result regarding the market price of the liquidity risk factor remains robust.
} 


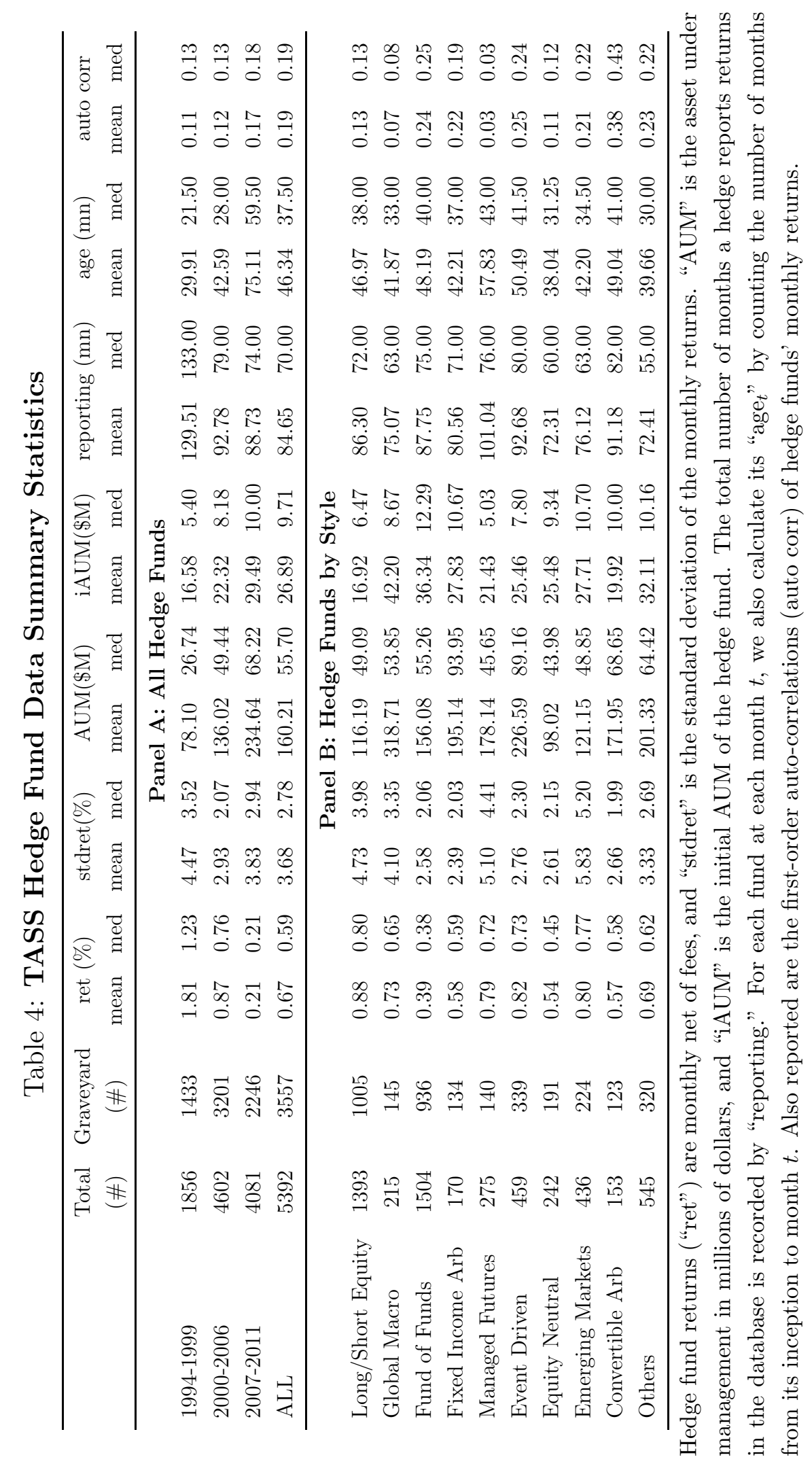




\section{Portfolio Formation by Noise Betas}

We follow the standard procedure of Fama and MacBeth (1973) to perform cross-sectional tests on the noise measure. Let $R_{t}^{i}$ be the month- $t$ excess return of hedge fund $i$, and we estimate its exposure to the noise measure by

$$
R_{t}^{i}=\beta_{0}+\beta_{i}^{N} \Delta \text { Noise }_{t}+\beta_{i}^{M} R_{t}^{M}+\epsilon_{t}^{i},
$$

where $\Delta$ Noise is the monthly change of our noise measure, $R^{M}$ is the excess return of CRSP value weighted portfolio, ${ }^{22}$ and $\beta_{i}^{N}$ and $\beta_{i}^{M}$ are estimates of fund $i$ 's exposures to the noise measure and the stock market risk.

Our specification in Equation (4) implicitly assumes that, other than the liquidity risk factor captured by our noise measure, the stock market risk is the main risk factor for hedge funds. Given the varying styles of hedge funds in our sample, it is perhaps a strong assumption. It is nevertheless a reasonable starting point as long as our noise measure is not a proxy for some well known risk factors other than liquidity risk, and, given our analysis in Section 3.3, this does not seem to be the case. We also experimented by adding other well known risk factors such as term spreads in the Treasury market and default spreads in the corporate bond market, and our results are robust. ${ }^{23}$ For this reason and to keep the specification simple, we will perform the cross-sectional test using our simple specification.

For each month $t$ and for each hedge fund $i$, we first use its previous 24 month returns to estimate the pre-ranking $\beta_{i}^{N}$ using Equation (4). We then sort the month- $t$ cross-section of hedge funds by their pre-ranking beta, $\beta_{i}^{N}$, into 10 portfolios. The post-ranking beta's of the 10 portfolios are estimated by

$$
R_{t}^{p}=\beta_{0}+\beta_{p}^{N} \Delta \text { Noise }_{t}+\beta_{p}^{M} R_{t}^{M}+\epsilon_{t}^{p}, \quad p=1, \ldots, 10 .
$$

where $R_{t}^{p}$ is the equal-weighted return for portfolio $p$ in month $t$ and this regression is done over the entire sample period. ${ }^{24}$

Table 5 reports the expected returns of the 10 noise-beta sorted portfolios and their postranking beta's. A negative noise beta implies that when the noise measure increases during

\footnotetext{
${ }^{22}$ We use the Fama-French research factors posted on Ken French's website.

${ }^{23}$ We also incorporated the hedge fund benchmarks proposed by Fung and Hsieh (2001), which can be downloaded from http://faculty.fuqua.duke.edu/dah7/DataLibrary/TF-FAC.xls. We regress the monthly changes of our noise measure on these factors and use the residual as our noise factor in the cross-sectional test. Our results remain robust. In other words, the unexplained component in our noise measure is important for the cross-sectional pricing of hedge funds.

${ }^{24}$ We also repeated our analysis by weighting hedge fund returns by their asset under manage (AUM). Our results are quite similar. In the cross-sectional test to be performed later in this section, we always include fund AUM as a control. Large funds on average under perform small funds, but the difference is small in magnitude.
} 
crises, the hedge fund returns decreases. In other words, a hedge fund with negative noise beta is the one with high exposure to liquidity risk. Among the 10 noise-beta sorted portfolios, portfolio 1 therefore has a much higher exposure to liquidity risk than portfolio 10, and we can loosely characterize the hedge funds in portfolio 1 as more aggressive and those in portfolio 10 as more conservative in taking liquidity risk.

More important for our cross-sectional pricing test, Table 5 also shows that hedge funds in portfolio 1 differ from those in portfolio 10 in average performance. Specifically, the aggressive funds outperform the conservative ones by a large margin. The average excess return for portfolio 1 is $0.95 \%$ per month compared with $0.23 \%$ for portfolio 10 , implying a superior monthly performance of $0.72 \%$. In fact, moving from portfolio 10 to 1 , there is a general pattern of increasing average returns, indicating improved performances with increasing exposures to the liquidity risk. One direct implication of this pattern of risk and return is that the liquidity risk as captured by our noise measure is priced, and this pricing implication will be formally tested later in this section as we perform cross-sectional tests a la Fama and MacBeth (1973).

To further understand these 10 noise-beta sorted portfolios, we report in Table 6 the characteristics of hedge funds within each portfolio. We see that the hedge funds in portfolios 1 and 10 are similar in their characteristics. Also reported in Table 6 is the relative allocation of hedge funds within each style category to the 10 portfolios. One interesting observation is that on average $29.62 \%$ of the hedge funds specializing in Emerging Markets show up in the aggressive portfolio. Other than that, the distribution does not seem to be very informative, although it does point to the fact that it is important to do the cross-sectional test at the hedge fund level. In particular, test the liquidity risk at the style indices level will not be a successful endeavor.

In Figure 4, we compare the liquidity risk of hedge funds in portfolio 1 versus portfolio 10 in a different way. For each year $t$, we report the one-year exit rate in the sample by calculating how many hedge funds among the live sample end up in graveyard by the end of year $t$. Conditioning on a fund's exit from live sample to graveyard, we also track which portfolio this fund belongs to prior to exiting. From Figure 4, we can see a distinctive increase in exit rate in 2008. This is hardly surprising given the severity of the financial crisis in 2008. What's interesting is that the exit rate is much higher for hedge funds in the aggressive category (portfolio 1), while hedge funds in the conservative category have similar exit rate as the sample average. It should be noted that hedge funds exit from the database for various reasons and death is only one of them. In fact, for the sample period excluding 2008, the hedge funds in portfolio 10 on average exit more often than those in portfolio 1 . This baseline makes the dramatic reversal in exit rate between the two portfolios even more interesting. 


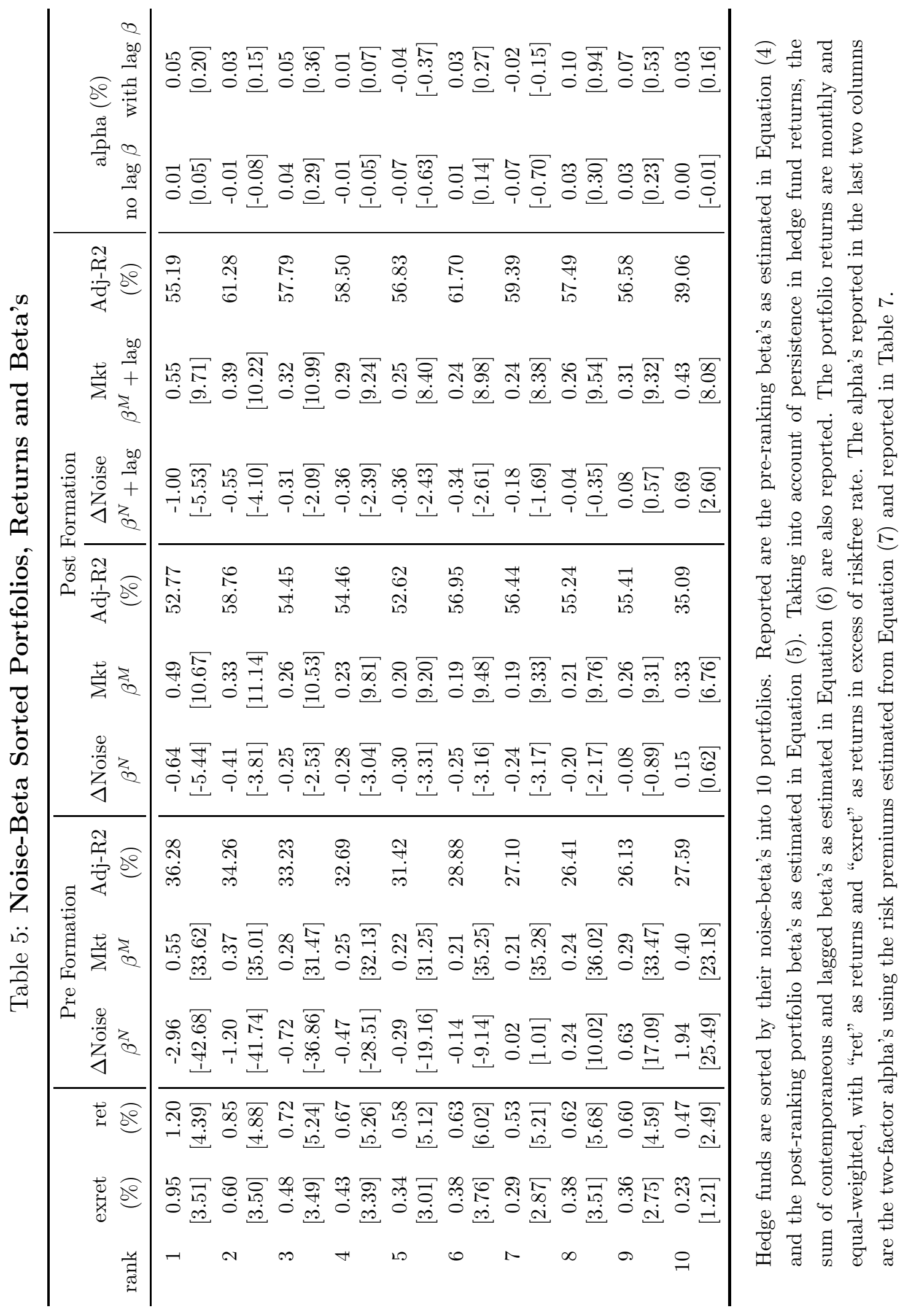


Table 6: Noise-Beta Sorted Portfolios, Characteristics

\begin{tabular}{lcccccccccc}
\hline Portfolio Rank & 1 & 2 & 3 & 4 & 5 & 6 & 7 & 8 & 9 & 10 \\
\hline & \multicolumn{7}{c}{ Panel A: Characteristics } \\
AUM (\$M) & 163 & 183 & 205 & 217 & 218 & 212 & 200 & 187 & 170 & 160 \\
iAUM (\$M) & 21.08 & 19.61 & 22.18 & 21.64 & 21.23 & 20.13 & 20.80 & 19.67 & 19.91 & 17.41 \\
reporting (mn) & 130 & 128 & 132 & 135 & 134 & 135 & 133 & 133 & 129 & 130 \\
age (mn) & 75.9 & 75.6 & 76.3 & 78.0 & 78.0 & 77.7 & 76.9 & 77.0 & 76.4 & 77.0 \\
stdret (\%) & 3.77 & 2.40 & 1.90 & 1.76 & 1.56 & 1.44 & 1.41 & 1.51 & 1.80 & 2.61 \\
auto corr & 0.15 & 0.19 & 0.22 & 0.23 & 0.25 & 0.25 & 0.23 & 0.20 & 0.16 & 0.11 \\
\hline & Panel B: Allocation & within & Hedge & Fund Style (\%) & & & \\
Long/Short Equity & 11.99 & 12.08 & 9.16 & 7.22 & 6.08 & 6.27 & 7.51 & 10.16 & 13.85 & 15.67 \\
Global Macro & 16.65 & 13.32 & 9.62 & 6.38 & 5.25 & 4.88 & 6.85 & 9.63 & 13.68 & 13.74 \\
Fund of Funds & 4.12 & 7.62 & 11.48 & 14.73 & 15.75 & 14.82 & 12.61 & 9.46 & 5.98 & 3.42 \\
Fixed Income Arb & 10.34 & 7.28 & 9.10 & 11.29 & 11.65 & 11.71 & 11.40 & 11.73 & 9.71 & 5.80 \\
Managed Futures & 17.79 & 9.80 & 5.41 & 4.17 & 3.92 & 4.13 & 5.46 & 8.16 & 13.76 & 27.41 \\
Event Driven & 4.87 & 8.33 & 10.91 & 11.16 & 12.23 & 12.91 & 12.62 & 12.65 & 8.68 & 5.63 \\
Equity Neutral & 3.69 & 7.30 & 9.94 & 8.15 & 7.90 & 9.61 & 11.95 & 13.83 & 16.85 & 10.77 \\
Emerging Markets & 29.62 & 15.91 & 9.86 & 6.30 & 4.87 & 4.54 & 5.12 & 6.22 & 7.57 & 10.00 \\
Convertible Arb & 11.33 & 12.71 & 11.93 & 11.18 & 12.42 & 12.70 & 12.39 & 8.48 & 5.12 & 1.73 \\
Others & 6.76 & 8.67 & 10.56 & 10.41 & 9.79 & 11.27 & 12.77 & 11.06 & 9.99 & 8.72 \\
\hline
\end{tabular}

The 10 portfolios are ranked by their noise beta's. See Table 4 for variable definitions.

\section{Hedge Fund Data Quality}

Given the voluntary nature of hedge fund reporting, we need to be concerned about how their exiting behavior might introduce biases to our results. For example, hedge funds might simply stop reporting after some poor performance. As a result, the dataset tends to overstate fund returns since those missing returns are likely to be much lower than the sample average. For our purpose, if this type of overstating is more prevalent among funds in portfolio 1, then it will contribute to the superior performance of portfolio 1 over portfolio 10 .

We address this issue by replacing the last month returns of all exiting funds by large negative numbers such as $-100 \%,-50 \%$, and $-20 \%$ and recalculate the average returns for the 10 portfolios. We see a marked reduction in average monthly returns across the 10 portfolios (especially when $-100 \%$ is used), but the relative performance of these 10 portfolios remains very much as that exhibited in Table 5. Applying this approach to the Fama-MacBeth crosssectional test to be performed later in this section, we find very little difference in the estimated liquidity risk premium. In fact, the point estimate for the liquidity risk premium is a bit stronger. This is because on average funds in portfolio 10 tend to exit more frequently than 


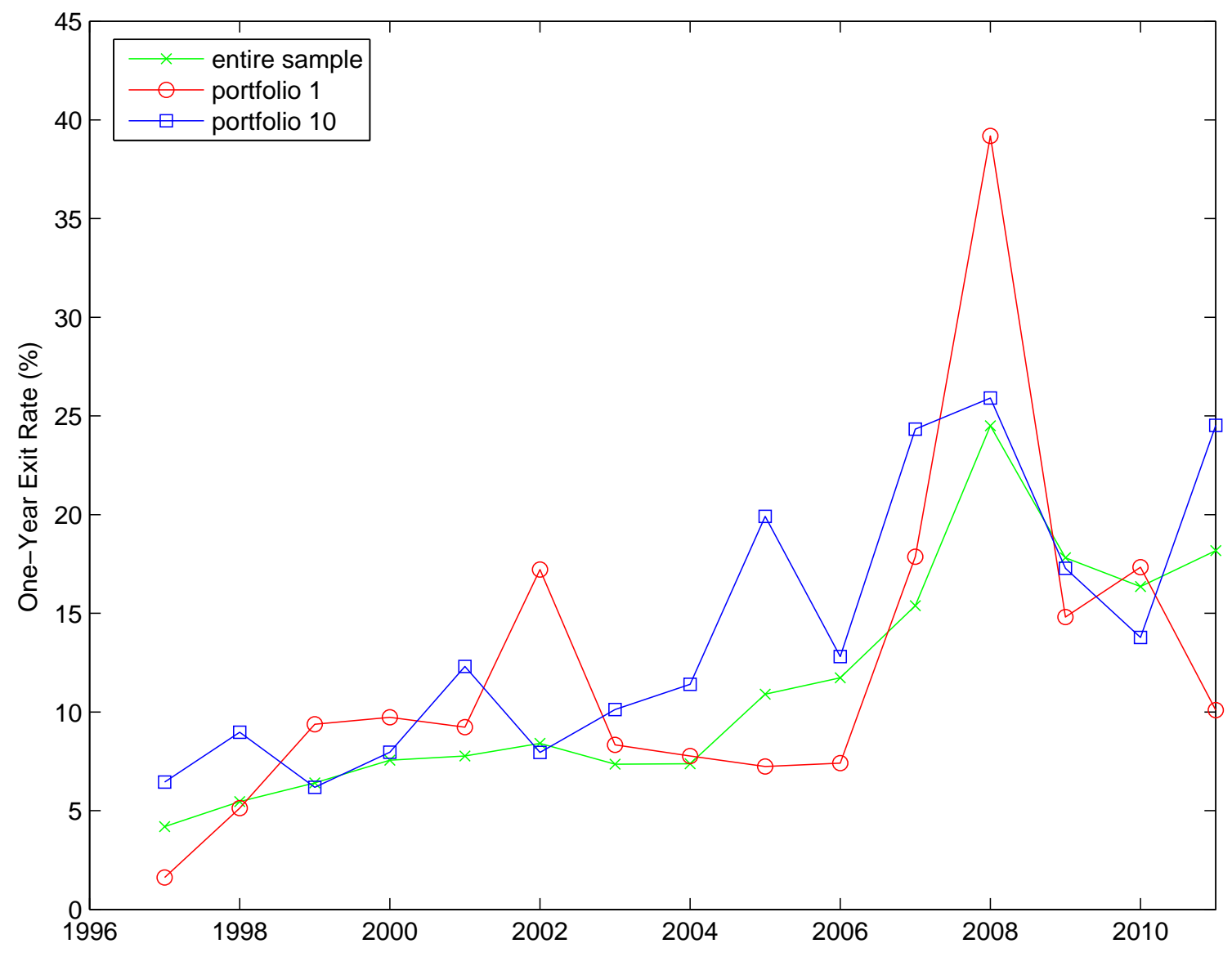

Figure 4: The year- $t$ exit rate of hedge funds in the top- and bottom-ranked noise-beta sorted portfolios.

those in portfolio 1, and 2008 was of one of the few exceptions when this pattern is reversed. ${ }^{25}$ Overall, we believe that our results are robust with respect to this particular issue of hedge fund data quality.

Another well known issue with respect to hedge fund data quality is the quality of the reported returns. In fact, previous research has found relatively large auto-correlation in hedge fund returns. As reported in the last two columns of Table 4, the monthly auto-correlation is on average $19 \%$. One possible explanation is return smoothing. While it would not have a large impact on average performance, it will distort risk exposure. Later in this section, we will introduce lagged beta's to better capture risk exposures of hedge funds.

\footnotetext{
${ }^{25}$ We further experimented with other ways to better extract information from the exit event. For example, we count the number of exit conditioning on lower performance, say bottom $25 \%$ of the sample. Again, this pattern across portfolios 1 and 10 remains the same.
} 


\section{Post-Ranking Noise Beta}

Also reported in Table 5 are the post-ranking noise beta's, which are estimated with satisfactory precisions and exhibit a close to monotonic relation to the portfolio rankings. This is an encouraging sign for our empirical test, given the importance of having a good measure of liquidity risk exposures. ${ }^{26}$ We sort hedge funds into portfolio 1 believing that their trading strategies are more exposed to the systematic liquidity risk. The large and negative postranking beta for portfolio 1 confirms that this is indeed the case: hedge funds in this portfolio tend to under perform when the noise measure spikes up during crises. Moving from portfolio 1 to portfolio 10, the post-ranking beta becomes less negative as the liquidity exposure lessens. This precision and consistency in the post-ranking noise beta's form an important foundation for our cross-sectional test to be performed in the next section.

We can further improve the precision of our risk exposure measures. As mentioned earlier, one issue that is unique to the hedge fund data is that their returns are known to be highly serially correlated. As shown in Getmansky, Lo, and Makarov (2004), one likely explanation is their illiquidity and the possibility of smoothed returns at the fund level. In this respect, a better way to capture a hedge fund's risk exposure is to regress its returns on the contemporaneous as well as the lagged factor. Using this intuition, we estimate the post-ranking beta by

$$
R_{t}^{p}=\beta_{0}+\beta_{p}^{N} \Delta \text { Noise }_{t}+\operatorname{lag} \beta_{p}^{N} \Delta \text { Noise }_{t-1}+\beta_{p}^{M} R_{t}^{M}+\operatorname{lag} \beta_{p}^{M} R_{t-1}^{M} .
$$

Given the high serial correlation in hedge fund returns, a more accurate estimate of a portfolio's exposure to liquidity risk is $\beta_{p}^{N}+\operatorname{lag} \beta_{p}^{N}$. As reported in Table 5 , there is much improvement in terms of the spread of post-ranking noise beta as well as the statistical significance of the postranking noise beta. It is also interesting to note that although the market exposure $\beta_{p}^{M}+\operatorname{lag} \beta_{p}^{M}$ also has some improvement, the improvement in noise beta is much more significant.

\section{Estimating Liquidity Risk Premiums using Fama-MacBeth Regressions}

Following Fama and MacBeth (1973), we perform the cross-sectional regression for each month $t$ :

$$
R_{t}^{i}=\gamma_{0 t}+\gamma_{t}^{N} \beta_{i}^{N}+\gamma_{t}^{M} \beta_{i}^{M}+c_{t}^{\text {age }} \operatorname{age}_{t}^{i}+c_{t}^{\mathrm{AUM}} \mathrm{AUM}_{t}^{i}+\epsilon_{t}^{i} .
$$

\footnotetext{
${ }^{26}$ Post-ranking beta's for risk factors other than the market portfolio are always difficult to estimate. It is usually difficult to construct portfolios with a strong enough spread in terms of their exposures to the particular risk factor of interest. For example, using cross-sectional stock returns to test the the VIX index, Ang, Hodrick, Xing, and Zhang (2006) have issues in constructing portfolios with strong spread in their postranking beta's. Facing a similar issue, Pastor and Stambaugh (2003) use predicted beta's. Specifically, they take advantage of stock characteristics that are more stable and postulate that their liquidity beta is an affine function of stock characteristics.
} 
where $R_{t}^{i}$ is the month- $t$ return of hedge fund $i, \beta_{i}^{N}$ and $\beta_{i}^{M}$ are the noise and market beta's of hedge fund $i$. Following Fama and French (1992), we assign the post-ranking portfolio beta's, which are estimated as in Equation (5), to each hedge fund in the portfolio. ${ }^{27}$ The fund's age and log of asset under management (AUM) are used as controls. The factor premiums are estimated as the time-series average of $\gamma_{t}^{N}$ and $\gamma_{t}^{M}$.

Table 7 reports the factor risk premiums for our noise measure as well as the market portfolio. The Fama-MacBeth t-stats are reported in squared brackets. We see that the liquidity risk as captured by our noise measure is indeed priced. The coefficient that corresponds to the noise risk premium is negative and statistically significant. When only contemporaneous post-ranking beta's are used in the test, the estimated coefficient is $-0.69 \%$ per month with a t-stat of -2.37 . When the sum of contemporaneous and lagged beta's, $\beta_{p}^{N}+\operatorname{lag} \beta_{p}^{N}$, are used in the cross-sectional test, the estimated coefficient is $-0.35 \%$ with a t-stat of $-2.52 .{ }^{28}$

Given that our noise measure moves up when the market-wide liquidity deteriorates, this means that the liquidity risk premium is positive and significant. Relating back to the earlier discussions on the relative performance of portfolios sorted by noise beta $\left(\beta^{N}\right)$ as reported in Table 5, this result provides a formal test in support of the intuition developed there. Specifically, the reason why hedge funds with high negative noise beta provide higher expected returns is because their high exposures to this priced liquidity risk.

Another way to see this result is to use the risk premiums estimated from this crosssectional test, plug it back to the two-factor model, and calculate the two-factor alpha's for the ten hedge fund portfolios. The last two columns of Table 5 report such alpha's. The first column is for the case when only contemporaneous post-ranking beta's are used in the crosssectional test, while the second column is for the case that uses both contemporaneous and lagged post-ranking beta's in the cross-sectional test. Unlike the unadjusted portfolio returns reported in the left two columns of Table 5, the two-factor alpha's are no longer significant, economically or statistically, and this is true for all ten hedge fund portfolios.

\section{Pricing Tests on Variations of Noise Measure}

In addition to the base case tests on the noise measure, we also perform hedge fund pricing tests on a few variations of the noise measure.

To take into account of the fact that bid/ask spreads in the Treasury market also have some time-variation, we scale our noise measure by the cross-sectional average of bid minus

\footnotetext{
${ }^{27}$ In addition to the 10 noise-beta sorted portfolio used here, we also perform our test using the $5 \times 5$ portfolios double-sorted by noise-beta and market-beta. Our results on the liquidity risk premium remains robust.

${ }^{28}$ The slope coefficient is smaller in the latter case due to the increased spread in noise beta's. We believe that including the lagged beta's is important in order to better capture hedge funds exposure to the liquidity risk.
} 
Table 7: Estimating Liquidity Risk Premiums using Hedge Fund Returns

\begin{tabular}{lccccc}
\hline Factor & Intercept & Liquidity & Market & Age & AUM \\
\hline \multirow{5}{*}{ Panel A: Noise as Proxy of Liquidity } \\
Noise & 1.73 & -0.69 & 1.01 & 0.015 & -0.10 \\
\multirow{4}{*}{ Noise (beta+lag beta) } & {$[4.39]$} & {$[-2.37]$} & {$[1.65]$} & {$[0.26]$} & {$[-3.96]$} \\
& 1.77 & -0.35 & 1.01 & 0.016 & -0.10 \\
Noise/BASpreads & {$[4.37]$} & {$[-2.52]$} & {$[1.8]$} & {$[0.29]$} & {$[-3.95]$} \\
& 1.75 & -0.56 & 0.89 & 0.009 & -0.10 \\
Noise-VIX-Default & {$[4.38]$} & {$[-2.20]$} & {$[1.49]$} & {$[0.16]$} & {$[-3.93]$} \\
& 1.65 & -1.19 & 0.97 & 0.008 & -0.10 \\
& {$[4.14]$} & {$[-2.26]$} & {$[1.67]$} & {$[0.15]$} & {$[-3.88]$} \\
\hline \multirow{4}{*}{ On5Y } & Panel B: Other & Proxies of Liquidity & & \\
& 2.00 & -1.58 & 0.63 & 0.003 & -0.10 \\
On10Y & {$[4.46]$} & {$[-0.79]$} & {$[0.93]$} & {$[0.04]$} & {$[-3.96]$} \\
& 1.80 & -0.70 & 1.05 & 0.002 & -0.09 \\
RefCorp & {$[4.03]$} & {$[-0.25]$} & {$[1.76]$} & {$[0.03]$} & {$[-3.8]$} \\
& 1.77 & -5.32 & 0.73 & 0.017 & -0.10 \\
PSLiq & {$[4.37]$} & {$[-1.27]$} & {$[1.22]$} & {$[0.31]$} & {$[-4.01]$} \\
& 1.87 & -0.02 & 0.84 & -0.032 & -0.09 \\
VIX & {$[4.51]$} & {$[-0.22]$} & {$[0.96]$} & {$[-0.59]$} & {$[-3.89]$} \\
& 1.79 & 1.92 & 0.65 & -0.004 & -0.09 \\
Default & {$[4.23]$} & {$[0.49]$} & {$[0.72]$} & {$[-0.08]$} & {$[-3.83]$} \\
& 1.88 & 8.27 & 1.17 & -0.015 & -0.09 \\
& {$[4.19]$} & {$[1.37]$} & {$[1.79]$} & {$[-0.28]$} & {$[-3.89]$} \\
\hline
\end{tabular}

Each proxy of liquidity is tested together with the equity market portfolio in a two-factor model using hedge fund returns, with age and size (AUM) as additional controls. The coefficients for age are reported as percentage points. The Fama-MacBeth t-stat's are reported in squared brackets. Panel A focuses on the noise measure with the base case as described in Equations (5) and (7) and additional cases. Panel B considers other proxies of liquidity. See Table 2 for variable definitions. 
ask yield for all of the bonds used in the construction of the noise measure. As shown in Panel A of Table 7, we find that this scaled version is priced with an estimated risk premium similar to the base case in magnitude and statistical significance.

We also construct a variation of our noise measure to take into account of the fact that the total amount outstanding varies across Treasury bonds. So instead of equal weighting the squared yield deviations across bonds, we weight them by the size of the bond. Effectively, the pricing errors of larger and therefore more liquidity bonds are weighted more. We find similar hedge fund pricing results for this variation of noise measure.

Our time-series analysis shows that our noise measure is related to other known proxies of liquidity including the VIX index and default spreads. To evaluate the relative importance of the information that is captured in our noise measure versus those in VIX and default spread, we perform our cross-sectional test on a noise measure that is orthogonal to these two variables. Specifically, we first regress the monthly changes of our noise measure on the monthly changes of VIX and default spreads, and then perform the pricing test using the residual. The result is reported in Table 7, the last row of Panel A, under the case "Noise-VIX-Default." We see that after taking out the information contained in VIX and default spreads, our noise measure maintains its significance and magnitude in pricing the cross-sectional hedge fund returns.

We repeat the same exercise by including the 5- and 10-year on-the-run premiums, the Refcorp spread, and the Pastor-Stambaugh liquidity factor along with the VIX index and default spreads in the regression. Performing the hedge fund pricing test on the residual, we again reach the same conclusion. That is, the importance of noise measure as a liquidity risk factor in pricing hedge funds is independent of these "usual suspects." While all of these variables are informative in their own right and for their respective market, we would like to argue that the information captured in our noise measure is unique. Given the breadth of hedge fund activities and their specialization on arbitrage activities and liquidity, we would further argue that this unique information contained in our noise measure is broad and important.

\section{Pricing Tests on Other Liquidity Proxies}

What we have established so far is that our noise measure is an important priced liquidity factor, above and beyond the information contained in other liquidity proxies such as the VIX index and default spreads. The remaining question is are these liquidity proxies important for the pricing of hedge fund returns? The importance of these proxies is widely known and they have been shown to be important for their respective markets. But what are their implications for the hedge fund returns?

For this purpose, we repeat the same hedge fund tests by replacing the noise measure with one of other liquidity proxies. This includes the on-the-run premiums for 5- and 10year Treasury bonds, the RefCorp spread, the Pastor-Stambaugh stock market liquidity risk 
factor, the VIX index, and default spreads. Again, we use the two-factor model including the stock market return and the liquidity risk factor. We perform the test by first sorting hedge funds by their exposures to the liquidity risk factor into 10 portfolios, and then perform the Fama-MacBeth cross-sectional test. As shown in Panel B of Table 7, we find no evidence that these risk factors are priced in hedge fund returns.

\subsection{Explaining Carry Trade Returns}

\section{Building Currency Portfolios}

Following Lustig, Roussanov, and Verdelhan (2011), we consider 36 currencies from both developed and emerging countries. Currencies are included in the sample only when both spot and forward rates are available. Our sample starts with 17 currencies, and reaches a maximum of 34 currencies. Since the launch of the Euro in January 1999, our sample covers 24 currencies only. For each country, we obtain its end-of-month spot and forward exchange rates with one-month maturity from Barclays and Reuters via Datastream. For both forward and spot rates, we use mid bid-ask quotes in units of foreign currency per U.S. dollar. The sample period spans from January 1987 to December 2011.

Let's denote the log of the one-month forward rate by $f$, and the log of the spot rate by $s$. At the end of each month $t$, we allocate all currencies into six carry trade portfolios based on their forward discount $f_{t}-s_{t}$. Because the covered interest parity holds closely at monthly frequency, our portfolios sorted on forward discounts $f_{t}-s_{t}$ are equivalent to portfolios ranked by interest rate differentials $i_{t}^{*}-i_{t}$, where $i_{t}^{*}$ and $i_{t}$ are the foreign and the U.S. one-month riskfree interest rates, respectively. Portfolio 6 contains the currencies with the smallest forward discounts (or lowest interest rates), and portfolio 1 contains the currencies with the biggest forward discounts (or highest interest rates). From the perspective of a U.S. investor, the log excess return $r x$ of holding a foreign currency in the forward market and then selling it in the spot market one month later at $t+1$ is:

$$
r x_{t+1}=f_{t}-s_{t+1}=i_{t}^{*}-i_{t}+s_{t}-s_{t+1}=i_{t}^{*}-i_{t}-\triangle s_{t+1} .
$$

The log currency excess return for a carry trade portfolio is then calculated as the equally weighted average of the log excess returns of all currencies in the portfolio. We re-balance carry trade portfolios at the end of every month in our sample period.

\section{Carry Trade Portfolios, Beta and Alpha}

For the six carry trade portfolios described in the previous section, we first estimate their factor risk exposures by

$$
R_{t}^{i}=\beta_{0}+\beta_{i}^{N} \Delta \text { Noise }_{t}+\beta_{i}^{M} R_{t}^{M}+\epsilon_{t}^{i},
$$


Table 8: Currency Carry Portfolios, Beta and Alpha

\begin{tabular}{|c|c|c|c|c|c|c|c|c|}
\hline \multirow[b]{3}{*}{ Rank } & \multirow[b]{3}{*}{$\begin{array}{c}\text { exret } \\
(\%)\end{array}$} & \multicolumn{6}{|c|}{ Panel A: Developed and Emerging Countries } & \multirow{3}{*}{$\begin{array}{c}\text { One Factor } \\
\Delta \text { Noise } \\
\text { beta }\end{array}$} \\
\hline & & \multicolumn{4}{|c|}{ Two Factor Model } & \multicolumn{2}{|c|}{ CAPM } & \\
\hline & & $\begin{array}{c}\Delta \text { Noise } \\
\beta^{N}\end{array}$ & $\begin{array}{c}\text { Market } \\
\beta^{M}\end{array}$ & $\begin{array}{c}\text { Adj-R2 } \\
(\%)\end{array}$ & $\begin{array}{c}\text { alpha } \\
(\%)\end{array}$ & beta & $\begin{array}{c}\text { alpha } \\
(\%)\end{array}$ & \\
\hline 1 & $\begin{array}{c}0.79 \\
{[4.56]}\end{array}$ & $\begin{array}{c}-0.57 \\
{[-1.84]}\end{array}$ & $\begin{array}{c}0.15 \\
{[2.64]}\end{array}$ & 11.10 & $\begin{array}{c}0.24 \\
{[1.38]}\end{array}$ & $\begin{array}{c}0.19 \\
{[3.08]}\end{array}$ & $\begin{array}{c}0.69 \\
{[3.22]}\end{array}$ & $\begin{array}{c}-0.83 \\
{[-2.51]}\end{array}$ \\
\hline 2 & $\begin{array}{c}0.35 \\
{[2.39]}\end{array}$ & $\begin{array}{l}-0.29 \\
{[-1.54]}\end{array}$ & $\begin{array}{c}0.15 \\
{[2.90]}\end{array}$ & 10.18 & $\begin{array}{c}-0.01 \\
{[-0.07]}\end{array}$ & $\begin{array}{c}0.17 \\
{[3.64]}\end{array}$ & $\begin{array}{c}0.26 \\
{[1.55]}\end{array}$ & $\begin{array}{c}-0.54 \\
{[-2.80]}\end{array}$ \\
\hline 3 & $\begin{array}{c}0.28 \\
{[2.14]}\end{array}$ & $\begin{array}{c}-0.32 \\
{[-1.41]}\end{array}$ & $\begin{array}{c}0.09 \\
{[1.98]}\end{array}$ & 6.96 & $\begin{array}{c}-0.04 \\
{[-0.34]}\end{array}$ & $\begin{array}{c}0.12 \\
{[2.36]}\end{array}$ & $\begin{array}{c}0.22 \\
{[1.39]}\end{array}$ & $\begin{array}{l}-0.48 \\
{[-1.93]}\end{array}$ \\
\hline 4 & $\begin{array}{c}0.15 \\
{[1.21]}\end{array}$ & $\begin{array}{c}-0.12 \\
{[-0.61]}\end{array}$ & $\begin{array}{c}0.07 \\
{[1.65]}\end{array}$ & 2.84 & $\begin{array}{c}-0.01 \\
{[-0.08]}\end{array}$ & $\begin{array}{c}0.08 \\
{[1.91]}\end{array}$ & $\begin{array}{c}0.11 \\
{[0.77]}\end{array}$ & $\begin{array}{c}-0.24 \\
{[-1.13]}\end{array}$ \\
\hline 5 & $\begin{array}{c}-0.05 \\
{[-0.38]}\end{array}$ & $\begin{array}{c}-0.14 \\
{[-0.66]}\end{array}$ & $\begin{array}{c}0.05 \\
{[1.34]}\end{array}$ & 2.19 & $\begin{array}{l}-0.21 \\
{[-1.72]}\end{array}$ & $\begin{array}{c}0.07 \\
{[1.52]}\end{array}$ & $\begin{array}{c}-0.08 \\
{[-0.58]}\end{array}$ & $\begin{array}{c}-0.23 \\
{[-0.97]}\end{array}$ \\
\hline 6 & $\begin{array}{c}-0.18 \\
{[-1.37]}\end{array}$ & $\begin{array}{c}-0.05 \\
{[-0.33]}\end{array}$ & $\begin{array}{c}0.00 \\
{[0.06]}\end{array}$ & 0.06 & $\begin{array}{l}-0.22 \\
{[-1.73]}\end{array}$ & $\begin{array}{c}0.01 \\
{[0.24]}\end{array}$ & $\begin{array}{c}-0.18 \\
{[-1.30]}\end{array}$ & $\begin{array}{l}-0.06 \\
{[-0.38]}\end{array}$ \\
\hline
\end{tabular}

Panel B: Developed Countries Only

\begin{tabular}{|c|c|c|c|c|c|c|c|c|}
\hline \multirow[b]{2}{*}{ Rank } & \multirow[b]{2}{*}{$\begin{array}{c}\text { exret } \\
(\%)\end{array}$} & \multicolumn{4}{|c|}{ Two Factor Model } & \multicolumn{2}{|c|}{ CAPM } & \multirow{2}{*}{ 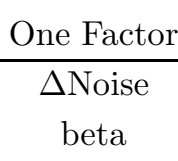 } \\
\hline & & $\begin{array}{c}\Delta \text { Noise } \\
\beta^{N}\end{array}$ & $\begin{array}{c}\text { Market } \\
\beta^{M}\end{array}$ & $\begin{array}{c}\text { Adj-R2 } \\
(\%)\end{array}$ & $\begin{array}{c}\text { alpha } \\
(\%)\end{array}$ & beta & $\begin{array}{c}\text { alpha } \\
(\%)\end{array}$ & \\
\hline 1 & $\begin{array}{c}0.53 \\
{[2.81]}\end{array}$ & $\begin{array}{l}-0.78 \\
{[-3.45]}\end{array}$ & $\begin{array}{c}0.13 \\
{[2.06]}\end{array}$ & 11.07 & $\begin{array}{l}-0.15 \\
{[-0.79]}\end{array}$ & $\begin{array}{c}0.19 \\
{[2.87]}\end{array}$ & $\begin{array}{c}0.43 \\
{[1.98]}\end{array}$ & $\begin{array}{l}-1.01 \\
{[-4.33]}\end{array}$ \\
\hline 2 & $\begin{array}{c}0.40 \\
{[2.35]}\end{array}$ & $\begin{array}{l}-0.69 \\
{[-2.51]}\end{array}$ & $\begin{array}{c}0.15 \\
{[2.95]}\end{array}$ & 14.78 & $\begin{array}{l}-0.25 \\
{[-1.50]}\end{array}$ & $\begin{array}{c}0.21 \\
{[3.37]}\end{array}$ & $\begin{array}{c}0.29 \\
{[1.48]}\end{array}$ & $\begin{array}{c}-0.96 \\
{[-3.14]}\end{array}$ \\
\hline 3 & $\begin{array}{c}0.25 \\
{[1.56]}\end{array}$ & $\begin{array}{l}-0.40 \\
{[-1.47]}\end{array}$ & $\begin{array}{c}0.12 \\
{[2.30]}\end{array}$ & 8.00 & $\begin{array}{l}-0.16 \\
{[-1.00]}\end{array}$ & $\begin{array}{c}0.15 \\
{[2.67]}\end{array}$ & $\begin{array}{c}0.17 \\
{[0.95]}\end{array}$ & $\begin{array}{c}-0.61 \\
{[-2.08]}\end{array}$ \\
\hline 4 & $\begin{array}{c}0.23 \\
{[1.47]}\end{array}$ & $\begin{array}{c}-0.18 \\
{[-0.59]}\end{array}$ & $\begin{array}{c}0.05 \\
{[1.01]}\end{array}$ & 1.48 & $\begin{array}{c}0.05 \\
{[0.29]}\end{array}$ & $\begin{array}{c}0.07 \\
{[1.26]}\end{array}$ & $\begin{array}{c}0.19 \\
{[1.04]}\end{array}$ & $\begin{array}{c}-0.26 \\
{[-0.84]}\end{array}$ \\
\hline 5 & $\begin{array}{c}0.03 \\
{[0.21]}\end{array}$ & $\begin{array}{l}-0.06 \\
{[-0.27]}\end{array}$ & $\begin{array}{c}0.02 \\
{[0.40]}\end{array}$ & 0.22 & $\begin{array}{l}-0.05 \\
{[-0.32]}\end{array}$ & $\begin{array}{c}0.03 \\
{[0.66]}\end{array}$ & $\begin{array}{c}0.01 \\
{[0.08]}\end{array}$ & $\begin{array}{c}-0.09 \\
{[-0.40]}\end{array}$ \\
\hline 6 & $\begin{array}{c}0.00 \\
{[0.01]}\end{array}$ & $\begin{array}{c}0.47 \\
{[2.04]}\end{array}$ & $\begin{array}{c}0.02 \\
{[0.27]}\end{array}$ & 1.73 & $\begin{array}{c}0.30 \\
{[1.63]}\end{array}$ & $\begin{array}{c}-0.01 \\
{[-0.19]}\end{array}$ & $\begin{array}{c}0.01 \\
{[0.04]}\end{array}$ & $\begin{array}{c}0.44 \\
{[2.15]}\end{array}$ \\
\hline
\end{tabular}

Portfolios are formed monthly by sorting currencies by their forward discount, with currencies in portfolio 1 having the highest forward discount and the highest interest rate while currencies in portfolio 6 having the lowest interest rate. Returns are monthly in excess of the risk-free rate. The two-factor model includes $\Delta$ Noise and stock market returns, and the two-factor alpha's are calculated using the factor risk premiums estimated using hedge fund returns. Also reported are the CAPM beta and alpha as well as the one-factor noise beta. 
where $R_{t}^{i}$ is the month- $t$ excess return of carry portfolio $i, R_{t}^{M}$ is the month- $t$ excess return of the aggregate stock market, and $\Delta$ Noise $_{t}$ is monthly change of our noise measure for month $t$.

Panel A of Table 8 reports, for the six currency carry portfolios, their respective risk exposures, $\beta^{N}$ and $\beta^{M}$, to the noise measure and the stock market portfolio. Currencies in portfolio 6 are those with the lowest interest rate and function as funding currencies, while currencies in portfolio 1 have the highest interest rate and are on the asset side of the carry trade. It is therefore interesting to see that the asset currencies in carry portfolio 1 have the most negative noise beta among the six portfolios, implying a worsening portfolio performance for such target curries during liquidity crises when our noise measure usually spikes up. By contrast, carry portfolio 6 have a small and statistically insignificant beta on our noise measure, implying very low exposure to liquidity risk. Moving from portfolio 1 to portfolio 6, we do observe a general pattern of decreasing liquidity exposure, although it is not monotonic.

Also reported in Table 8 are the mean excess returns for the six portfolios. As expected, moving from portfolio 6 to 1, the monthly mean excess return increases monotonically from -18 basis points to 79 basis points, and this difference in performance is the main driver behind the popularity of currency carry trades. Connecting this pattern in expected returns to that in liquidity risk exposures $\beta^{N}$, one could argue that the superior performance of portfolio 1 is a result of its high exposure to liquidity risk.

To formally test this idea, we use the factor risk premiums estimated using hedge fund returns (Table 7 ) to calculate the two-factor alpha for these six carry portfolios. ${ }^{29}$ Effectively, we are using the pricing information obtained from the hedge fund tests to see whether or not this information can help explain away the superior performance of currency carry trade. Our results in Table 8 show that it does work in the right direction. Without risk adjustment, the monthly expected return of portfolio 1 is 79 basis points with a t-stat of 4.56 . After adjusting for its risk exposures to our noise measure and the stock market portfolio, however, its monthly expected return is only 24 basis point with a t-stat of 1.38 . Similarly, the positive and statistically significant expected returns to portfolios 2 and 3 shrink to near zero after the risk adjustments.

By contrast, using the stock market alone in a one-factor model cannot help away the carry profits. As reported in Table 8, the CAPM alpha for portfolio 1 is 69 basis points per month with a t-stat of 3.08, which is large in magnitude and statistical significance. For

\footnotetext{
${ }^{29}$ We compute alpha by calculating the difference between the mean excess return for each portfolio and the mean excess return implied by the two factor model, using the liquidity and market risk premiums estimated from the hedge fund tests. In an earlier version of the paper, we use these six carry portfolios to test and estimate the liquidity risk premium. We find significant results. But given the limited number of test portfolios, we feel that this test is perhaps not very reliable. So we decide to use the risk premiums estimated using the hedge fund returns to explain the carry profits.
} 
comparison, we also report the one-factor noise beta in Table 8. Unlike the CAPM beta, the one-factor noise beta exhibits a very strong pattern of increasing liquidity exposure moving from portfolio 6 to portfolio $1 .{ }^{30}$

\section{Carry Portfolios with Developed Countries Only}

As a robustness check, we also test our results on 14 developed countries: Australia, Belgium, Canada, Denmark, France, Germany, Italy, Japan, Netherlands, New Zealand, Norway, Sweden, Switzerland and United Kingdom. This smaller sample starts with 14 countries and covers 10 countries after the launch of the Euro in January 1999. The results are summarized in Panel B of Table 8.

Again, we see that a pattern of increasing exposures to liquidity risk as we move from portfolio 6 that contains funding currencies to portfolio 1 that contains target currencies. For this subsample including currencies from developed countries only, we can estimate the noise beta's with better precision, and the pattern of increasing liquidity exposure is indeed monotonic. Without risk adjustment, portfolio 1 provides an average excess return of 53 basis points per month. With risk adjustment, however, the two-factor alpha shrinks to -15 basis points with a insignificant t-stat of 0.79 . By contrast, using only the market portfolio as risk adjustment, the CAPM alpha is 43 basis points with a t-stat of 1.98 .

This robustness result is also consistent with what we find using other carry trade indices. Given the popularity of carry trade, there are several existing carry trade indices provided by money managers. The JP Morgan IncomeFX index is one of them and it focuses on 14 currency pairs of developed countries. Using its monthly returns from November 1995 through December 2011, we find that this index return has a noise beta of -0.833 with a t-stat of -2.70 . Without any risk adjustment, its average monthly returns in excess of risk free rate is 59.7 basis points with a t-stat of 2.35. After adjust for risk exposures, however, its two-factor alpha is no longer statistically significant.

\section{Conclusions}

In this paper, we use price deviations from asset fundamentals as a measure of market illiquidity. Instead of focusing the liquidity condition of a specific market, we are interested in the liquidity conditions of the overall market. For this purpose, we consider the U.S. Treasury market, which is arguably the most important and one of the most liquid markets. Presum-

\footnotetext{
${ }^{30} \mathrm{We}$ cannot use the liquidity risk premium estimated in a two-factor model to calculate the one-factor alpha, although it should be convincing to the reader that it is the liquidity risk that helps explain the carry trade profits.
} 
ably, signs of illiquidity in this market reflects a general shortage of arbitrage capital and tightening of liquidity in the overall market, whatever its origins and causes. In particular, we use the average "pricing errors" in U.S. Treasuries as a measure of illiquidity of the aggregate market. Indeed, we found that this measure spikes up during various market crises, ranging from the 1987 stock market crash, the near collapse of LTCM, 9/11, GM credit crisis, to the fall of Bear Stearns and Lehman Brothers. This drastic variation of our illiquidity measure over time, especially during crisis, suggests that it represents substantial market-wide liquidity risk.

We further explore the pricing implications of this liquidity risk factor by examine its connection with the returns on assets/trading strategies that are generally thought to be sensitive to market liquidity conditions. Two sets of such returns are considered: returns from hedge funds and currency carry trades. We found that the market-wide liquidity risk, as measured by the variation in the price noise of Treasuries, can help to explain both the crosssectional variation in hedge fund returns and currency carry trade strategies, while various liquidity-related risk factors obtained from other markets such as equity, corporate bonds and equity options show no explanatory power. 


\section{Appendix: Robustness on Curve Fitting}

In this Appendix, we investigate the robustness of our result with respect to the particular curve-fitting method employed in Section 2.2. For this, we use two variations of the cubicspline method to fit the yield curve and then construct new noise measures based on the fitted curves. We find that the information content in these alternative noise measures is very similar to that found for the original one. Moreover, our main results remain quite robust with respect to the various curve-fitting methods.

\section{A Cubic Spline}

Spline-based methods use piecewise polynomials that are smoothly joined at selected knots to approximate the yield or forward curve. Cubic polynomials have been widely used for this purpose (McCulloch $(1971,1975))$. One of the short-comings of this cubic spline method is that it tends to generate unstable and oscillating yield curves that are absent of economic content. Fisher, Nychka, and Zervos (1995) improves on the traditional cubic spline method by introducing a roughness penalty function. This smoothing spline method trades off between the goodness-of-fit and the smoothness of the forward yield curve.

We assume that the instantaneous forward curve is a cubic spline with knot points on $\left(t_{0}, t_{1}, \ldots, t_{k}\right)$. On each of the subintervals $\left[t_{i-1}, t_{i}\right]$, with $1 \leq i \leq k$, the forward rate $f$ is a cubic polynomial function in maturity $m$ :

$$
f(m, b)=a^{i}\left(\frac{m-t_{i-1}}{t_{i}-t_{i-1}}\right)^{3}+b^{i}\left(\frac{m-t_{i-1}}{t_{i}-t_{i-1}}\right)^{2}+c^{i}\left(\frac{m-t_{i-1}}{t_{i}-t_{i-1}}\right)+d^{i},
$$

where $b=\left(\left(a^{i}, b^{i}, c^{i}, d^{i}\right), i=1,2, \ldots, k\right)$ summarizes the cubic spline parameters. In addition, we require that both $f$ and its first derivative are continuous at the connecting knot points over the $k$ subintervals. We also impose the constraints that $d^{0}>0$ and $a^{k}>0$ to ensure that forward rates are positive at maturities of zero and infinity.

Given the the forward curve, the zero-coupon yield curve can be derived and, similar to Section 2.2, the model parameters $b_{t}$ can be estimated using the market-observed Treasury bond and bill prices by:

$$
b_{t}=\underset{b}{\operatorname{argmin}}\left[\sum_{i=1}^{N_{t}}\left[\left(P^{i}(b)-P_{t}^{i}\right) \times \frac{1}{D_{i}}\right]^{2}+\lambda \int_{0}^{t_{k}}\left[f^{\prime \prime}(x, b)\right]^{2} d x\right],
$$

where $\lambda \geq 0$ and $f^{\prime \prime}(x, b)$ is the second derivative of the forward rate function with respect to maturity $x$. Compared to Equation (2) used earlier for curve fitting, the above objective function includes a roughness penalty function, which measures the curvature of the forward curve. As mentioned earlier, this penalty function was introduced by Fisher, Nychka, and 
Zervos (1995) to curtail the stability issue inherent in cubic spline method and has been widely used in the fixed-income community. With a small or close to zero penalty coefficient $\lambda$, the emphasis is on fitting the curve well at the potential cost of having a highly fluctuating forward curve. An increasing $\lambda$ will produce smoother forward curve, at the sacrifice of the goodness of fit. We will experiment with various $\lambda$ with the objective to find a flexible enough curve that fits the data well but doesn't oscillate too much to over-fit the data. ${ }^{31}$

\section{B Noise Measure Constructed using Cubic Spline}

We consider two cases of cubic spline. In the first case, we pick three subintervals that are joined at the knot points of 2-, 5-, and 10-year maturities. Given the importance of these maturities in the Treasury bond market, we feel that this is a natural choice. There are four parameters for each sub-interval, resulting in 12 parameters. The smoothness conditions at the 2- and 5-year maturity junctions take away 4 degrees of freedom. Consequently, we have 8 free parameters in our curve fitting and we call this specification "Cubic8." Compared with the Svensson model used earlier, Cubic8 has two more free parameters. To further relax the specification and give the curve fitting more degrees of freedom, we consider a second case with more subintervals: $(0,1 m, 3 m, 6 m, 1 y, 2 y, 3 y, 5 y, 7 y, 10 y)$. The knot points are chosen so that we have similar number of bonds and bills within each subinterval. We call this specification "Cubic20," since it has 20 free parameters in curve fitting.

We perform curve fitting using cubic spline from 1994 through 2011 with a monthly frequency. This is because the main robustness check we would like to perform is on the hedge fund test results. Setting the roughness penalty coefficient $\lambda$ to zero, we find that the correlations between our original noise measure and the alternatives constructed using cubic spline are $97.76 \%$ and $98.60 \%$, respectively, for Cubic8 and Cubic20. In other words, even with a more flexible curve fitting approach with 20 free parameters and zero requirement for smoothness, the resulting noise measure is closely related to our original noise measure. This is not surprising given that the noise measure is an aggregate of pricing errors across hundreds of bonds. If we further impose a smoothness requirement by setting the roughness penalty coefficient $\lambda=0.01$, the correlations increase to $98.99 \%$ and $99.03 \%$, respectively, for Cubic 8 and Cubic20. Given that our pricing tests are on the monthly changes of noise measure, it is also instructive to report the correlations in changes. With $\lambda=0$, the numbers are $83.30 \%$ and $88.59 \%$, respectively for Cubic8 and Cubic20. With $\lambda=0.01$, the numbers increase to $90.74 \%$ and $91.91 \%$, respectively for Cubic8 and Cubic20. We further perform the same set of timeseries analysis reported in Table 2 and find similar results. Not surprisingly, the information

\footnotetext{
${ }^{31}$ The penalty coefficient $\lambda$ is often allowed to vary according to maturity $m$ so as to fine tune the trade-off over different regions on the term structure. We decide to keep a simple specification with a constant $\lambda$.
} 

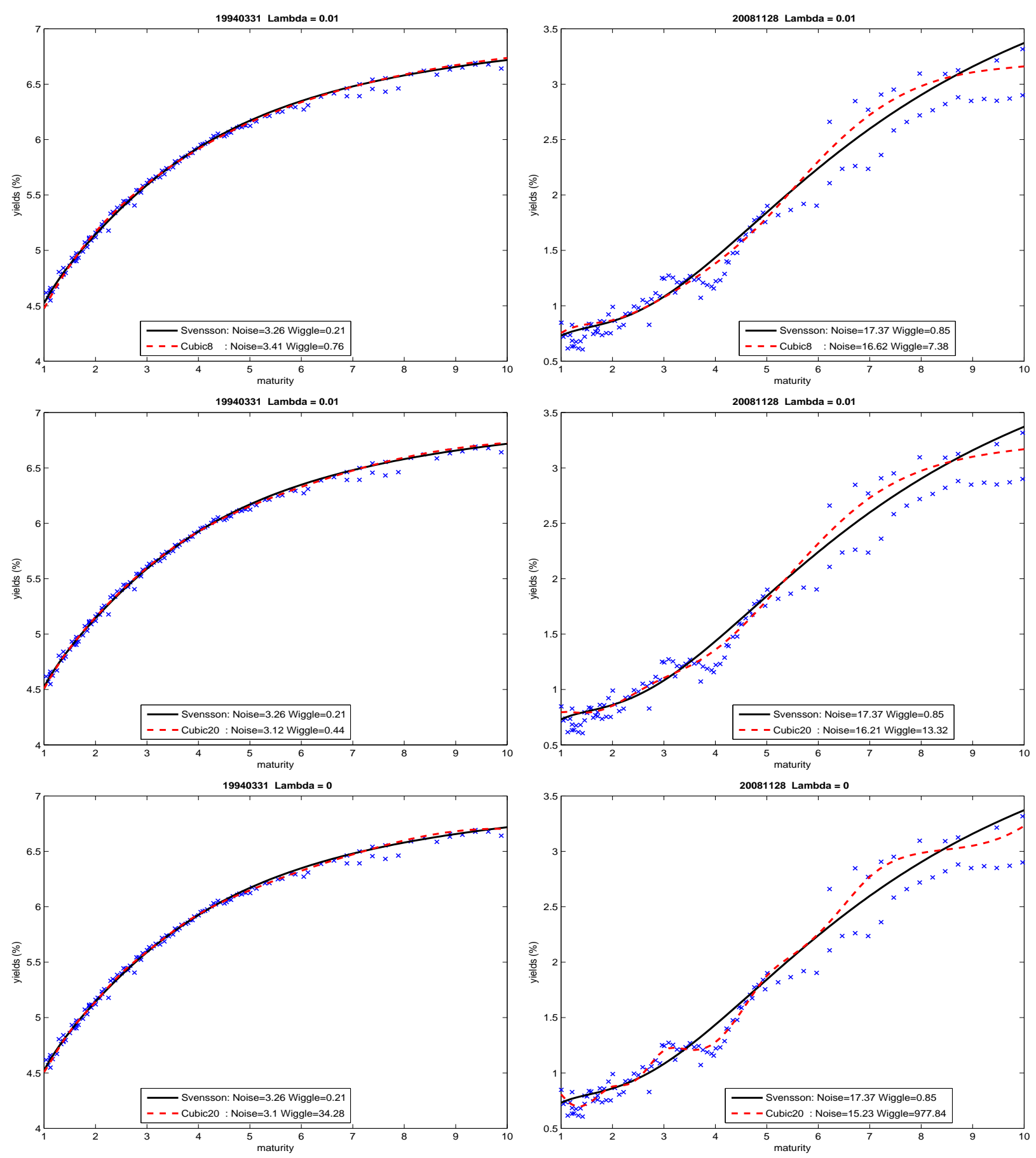

Figure AI: Examples of par-coupon yield curves and the market-observed bond yields, marked by "x". Left panels are for a normal day on 19940331, while right panels are for a stressful day on 20081130. The Svensson model is the base case in all figures and is marked by solid lines in black. The cubic-spline models are marked by dashed lines in red. The first row plots Cubic 8 with $\lambda=0.01$, the second row plots Cubic20 with $\lambda=0.01$ and the last row plots Cubic20 with $\lambda=0$. Marked in the legend are the levels of noise measure and "wiggle" - integrated curvature of the forward curve. 
content in these alternative noise measures is very similar to that found for the original one.

Figure AI provides more textured information with respect to how the curves fitted using cubic splines might differ those using the Svensson model. On the left panels, we plot the parcoupon yield curves along with the market observed bond yields for a normal day on March 31,1994 . As we can see, the shape of the curve as well as the level of the noise measure are pretty similar regardless of the curve fitting method or the choice of the roughness penalty coefficient $\lambda$. Even when $\lambda$ is set to zero in the last row, we see only a tiny improvement in the goodness of fit as captured by the noise measure. The only signal that sets this case apart from the others is the magnitude of "wiggle," which is integrated curvature of the forward curve (the penalty term in Equation A1). For the case of Cubic20 with $\lambda=0$, there is no requirement on smoothness and the wiggle is at 34.28. By contrast, the wiggle is only at 0.44 for the case of Cubic20 with $\lambda=0.01$ and 0.21 for the Svensson model. Regardless of their differences in wiggle, the noise measures produced by all four cases are very close.

For November 28, 2008, however, the differences in yield curves are more noticeable. In particular, using cubic spline does improve the goodness of fit. For example, the noise measure using the Svensson model is 17.37 basis points. It decreases to 16.62 basis points using Cubic8 with $\lambda=0.01$. Using Cubic20 with no penalty further improves the goodness of fit and the noise measure is at 15.23 basis points. Given the severity of the crisis during November and December 2008, this difference in yield curve fitting is probably among the most extreme in our sample. Nevertheless, we see that the noise measure is at 15.23 basis points even for Cubic20 with $\lambda=0$. In other words, the actual magnitude might vary from one curve fitting method to another, but the important feature of our noise measure remains very much the same. We would further argue that the main insight of our paper is in fact a quite general one: Using any yield curve as a benchmark for pricing, we can construct a noise measure. As long as this benchmark is generated by a smooth enough yield curve, which takes into account the internal consistency of bond pricing, the corresponding noise measure contains valuable information about the broad market liquidity.

\section{Cross-Sectional Tests using Hedge Fund Returns}

We use the noise measure constructed from the cubic spline method to perform the hedge fund test. The results for portfolio returns and post-ranking noise beta's are similar, which we will omit. Instead, we report in Table AI the estimated risk premiums for the two factor model. Panel A reports the pricing results for both Cubic8 and Cubic20 while fixing the roughness penalty coefficient $\lambda$ at 0.01 . As we can see that the estimated market prices of risk for our noise measure are negative and significant, and our main results using the original noise measure remain robust.

To further understand how sensitive our results are with respect to the choice of the 
Table AI: Estimating Liquidity Risk Premiums using Hedge Fund Returns

\begin{tabular}{l|cc|cc}
\hline \multirow{2}{*}{ Panel A: with fixed penalty coefficient $\lambda=0.01$} \\
& \multicolumn{2}{|c}{ Cubic8 } & \multicolumn{2}{c}{ Cubic20 } \\
& Liquidity & Market & Liquidity & Market \\
\hline \multirow{2}{*}{ Noise } & -0.61 & 0.88 & -0.49 & 1.44 \\
& {$[-2.23]$} & {$[1.51]$} & {$[-2.14]$} & {$[2.23]$} \\
Noise(beta+lag beta) & -0.30 & 0.79 & -0.29 & 1.21 \\
& {$[-2.28]$} & {$[1.57]$} & {$[-2.26]$} & {$[2.16]$} \\
Noise/BASpreads & -0.46 & 1.00 & -0.40 & 1.23 \\
& {$[-1.97]$} & {$[1.74]$} & {$[-1.99]$} & {$[1.95]$} \\
Noise-VIX-Default & -1.19 & 1.27 & -1.17 & 2.50 \\
& {$[-2.12]$} & {$[2.06]$} & {$[-2.11]$} & {$[2.97]$} \\
\hline
\end{tabular}

\begin{tabular}{|c|c|c|c|c|}
\hline \multicolumn{5}{|c|}{ Panel B: with varying penalty coefficient $\lambda$} \\
\hline & \multicolumn{2}{|c|}{ Cubic8 } & \multicolumn{2}{|c|}{ Cubic20 } \\
\hline & Liquidity & Market & Liquidity & Market \\
\hline$\lambda=0$ & $\begin{array}{l}-0.83 \\
{[-1.70]}\end{array}$ & $\begin{array}{c}0.76 \\
{[1.22]}\end{array}$ & $\begin{array}{l}-0.33 \\
{[-1.68]}\end{array}$ & $\begin{array}{c}1.10 \\
{[1.83]}\end{array}$ \\
\hline$\lambda=0.005$ & $\begin{array}{c}-0.71 \\
{[-2.17]}\end{array}$ & $\begin{array}{c}0.81 \\
{[1.37]}\end{array}$ & $\begin{array}{c}-0.45 \\
{[-1.94]}\end{array}$ & $\begin{array}{c}1.54 \\
{[2.39]}\end{array}$ \\
\hline$\lambda=0.01$ & $\begin{array}{c}-0.61 \\
{[-2.23]}\end{array}$ & $\begin{array}{c}0.88 \\
{[1.51]}\end{array}$ & $\begin{array}{l}-0.49 \\
{[-2.14]}\end{array}$ & $\begin{array}{c}1.44 \\
{[2.23]}\end{array}$ \\
\hline$\lambda=0.02$ & $\begin{array}{c}-0.53 \\
{[-2.19]}\end{array}$ & $\begin{array}{c}0.74 \\
{[1.25]}\end{array}$ & $\begin{array}{c}-0.47 \\
{[-2.10]}\end{array}$ & $\begin{array}{c}1.34 \\
{[2.04]}\end{array}$ \\
\hline$\lambda=0.03$ & $\begin{array}{c}-0.50 \\
{[-2.08]}\end{array}$ & $\begin{array}{c}0.77 \\
{[1.28]}\end{array}$ & $\begin{array}{c}-0.51 \\
{[-2.22]}\end{array}$ & $\begin{array}{c}1.19 \\
{[1.86]}\end{array}$ \\
\hline$\lambda=0.04$ & $\begin{array}{c}-0.49 \\
{[-2.05]}\end{array}$ & $\begin{array}{c}0.76 \\
{[1.23]}\end{array}$ & $\begin{array}{c}-0.48 \\
{[-2.10]}\end{array}$ & $\begin{array}{c}1.18 \\
{[1.83]}\end{array}$ \\
\hline$\lambda=0.05$ & $\begin{array}{l}-0.48 \\
{[-2.00]}\end{array}$ & $\begin{array}{c}0.79 \\
{[1.26]}\end{array}$ & $\begin{array}{c}-0.44 \\
{[-2.02]}\end{array}$ & $\begin{array}{c}1.19 \\
{[1.81]}\end{array}$ \\
\hline
\end{tabular}

The noise measure is tested together with the equity market portfolio in a two factor model using hedge fund returns, with age and size as additional controls. The Fama-MacBeth t-stat's are reported in squared brackets. The noise measure is constructed using two cubic spline methods: Cubic 8 and Cubic20. Reported in the table are the estimated market prices of risk for our noise measure and the equity market portfolio. 
roughness penalty coefficient $\lambda$, we report in Panel B of Table AI the pricing results with varying penalty coefficients. In each case, we perform month-by-month curve fitting with the chosen $\lambda$ and cubic spline method and then construct the noise measure using the fitted curve. We then perform the hedge fund test on the noise measure and report the market prices of risk. As we can see, our results remain quite robust. Except for the case when no roughness penalty is imposed, our pricing results remain pretty strong with respect to the varying choices of $\lambda$. Even for the case with no roughness penalty $(\lambda=0)$, our estimated coefficients are in the right direction and are marginally significant. Overall, these robustness checks confirm that indeed our results are quite general and is not an artifact of the curve fitting method. 


\section{References}

Acharya, V. V. and L. H. Pedersen (2005). Asset Pricing with Liquidity Risk. Journal of Financial Economics 77(2), 375-410.

Ang, A., R. Hodrick, Y. Xing, and X. Zhang (2006). The Cross-Section of Volatility and Expected Returns. Journal of Finance 61, 259-299.

Backus, D., S. Foresi, and C. Telmer (2001). Affine Term Structure Models and the Forward Premium Anomaly. Journal of Finance 56, 279-304.

Backus, D., A. Gregory, and C. Telmer (1993). Accounting for Forward Rates in Markets for Foreign Currency. Journal of Finance 48, 1887-1908.

Bao, J., J. Pan, and J. Wang (2011). The Illiquidity of Corporate Bonds. Journal of Finance 66, 911-946.

Billio, M., M. Getmansky, and L. Pelizzon (2010). Crises and Hedge Fund Risk. Working Paper, University of Massachusetts, Amherst.

Brunnermeier, M., S. Nagel, and L. H. Pedersen (2008). Carry Trades and Currency Crashes. NBER Macroeconomics Annual 23, 313-348.

Brunnermeier, M. K. and L. H. Pedersen (2009). Market Liquidity and Funding Liquidity. Review of Financial Studies 22, 2201-2238.

Burnside, C., M. Eichenbaum, I. Kleshchelski, and S. Rebelo (2010). Do Peso Problems Explain the Returns to the Carry Trade? Working Paper, Northwestern University.

Campbell, J., S. Grossman, and J. Wang (1993). Trading Volume and Serial Correlation in Stock Returns. Quarterly Journal of Economics 108, 905-939.

Cao, C., Y. Chen, B. Liang, and A. Lo (2010). Can Hedge Funds Time Market Liquidity? Working Paper, MIT Sloan School of Management.

Coval, J. and E. Stafford (2007). Asset fire sales (and purchases) in equity markets. Journal of Financial Economics 86, 479-512.

Duffie, D. (2010). Asset Price Dynamics with Slow-Moving Capital. Journal of Finance 65, $1238-1268$.

Fama, E. (1984). Forward and Spot Exchange Rates. Journal of Monetary Economics 14, 319-338.

Fama, E. and K. French (1992). The Cross-Section of Expected Stock Returns. Journal of Finance 47, 427-465.

Fama, E. and J. MacBeth (1973). Risk, Return, and Equilibrium: Empirical Tests. Journal of Political Economy 81, 607-36. 
Fisher, M., D. Nychka, and D. Zervos (1995). Fitting the term structure of interest rates with smoothing splines. Finance and Economics Discussion Series, Board of Governors of the Federal Reserve System 1.

Fleckenstein, M., F. A. Longstaff, and H. Lustig (2010). why does the treasury issue tips? the tipstreasury bond puzzle. Working Paper, UCLA Andersen School.

Fung, W. and D. A. Hsieh (2001). The Risk in Hedge Fund Strategies: Theory and Evidence from Trend Followers. The Review of Financial Studies 14, 313-341.

Getmansky, M., A. Lo, and I. Makarov (2004). An Econometric Model of Serial Correlation and Illiquidity in Hedge Fund Returns. Journal of Financial Economics 74, 529-609.

Gromb, D. and D. Vayanos (2002). Equilibrium and Welfare in Markets with Financially Constrained Arbitrageurs. Journal of Financial Economics 66, 361-407.

Jankowitsch, R., A. Nashikkar, and M. G. Subrahmanyam (2011). Price dispersion in OTC markets: A new measure of liquidity. Journal of Banking E3 Finance 35, 343-357.

Jurek, J. (2009). Crash-Neutral Currency Carry Trades. Working Paper, Princeton University.

Kyle, A. and W. Xiong (2001). Congagion as a Wealth Effect. Journal of Finance 62, $247-292$.

Lamoureux, C. and G. Theocharides (2012). Coupon Spreads and Illiquidity in the Market for 10-Year Treasury Notes. Working Paper, The University of Arizona.

Leland, H. and M. Rubinstein (1988). Comments on the Market Crash: Six Months After. Journal of Economic Perspectives 2(3), 45-50.

Longstaff, F. (2004). The Flight-to-Liquidity Premium in U.S. Treasury Bond Prices. Journal of Business 77, 511-525.

Lou, D., H. Yan, and J. Zhang (2012). Anticipated and Repeated Shocks in Liquid Markets. Working Paper, LSE and Yale.

Lustig, H., N. Roussanov, and A. Verdelhan (2011). Common Risk Factors in Currency Markets. Review of Financial Studies, forthcoming.

Mancini, L., A. Ranaldo, and J. Wrampelmeyer (2012). Liquidity in the Foreign Exchange Market: Measurement, Commonality, and Risk Premiums. Journal of Finance, Forthcoming.

McCulloch, J. H. (1971). Measuring the Term Structure of Interest Rates. Journal of Business 44, 19-31.

McCulloch, J. H. (1975). The Tax-Adjusted Yield Curve. Journal of Finance 30, 811-830. 
Merton, R. (1987). A Simple Model of Capital Market Equilibrium with Incomplete Information. Journal of Finance 42(3), 483-510.

Mitchell, M., L. H. Pedersen, and T. Pulvino (2007). Slow Moving Capital. The American Economic Review, P\&YP 97, 215-220.

Mitchell, M. and T. Pulvino (2011). Arbitrage Crashes and the Speed of Capital. Journal of Financial Economics, forthcoming.

Musto, D., G. Nini, and K. Schwarz (2011). Notes on Bonds: Liquidity at all Costs in the Great Recession. Working Paper, The Wharton School.

Nagel, S. (2011). Evaporating Liquidity. Working Paper, Stanford University.

Nelson, C. R. and A. F. Siegel (1987, October). Parsimonious Modeling of Yield Curves. Journal of Business 60(4), 473-89.

Pastor, L. and R. Stambaugh (2003). Liquidity Risk and Expected Stock Returns. Journal of Political Economy 111, 642-685.

Sadka, R. (2010). Liquidity Risk and the Cross-Section of Hedge-Fund Returns. Journal of Financial Economics 98, 54-71.

Shleifer, A. and R. Vishny (1997). The Limits of Arbitrage. Journal of Finance 52, 35-55.

Svensson, L. (1994). Estimating and Interpreting Forward Interest Rates: Sweden 1992 1994. Working Paper 4871, National Bureau of Economic Research.

Vayanos, D. and J.-L. Vila (2009). A Preferred-Habitat Model of the Term Structure of Interest Rates. Working Paper, London School of Economics.

Verdelhan, A. (2010). A Habit-Based Explanation of the Exchange Rate Risk Premium. Journal of Finance 65, 123-145. 